\title{
Life Course Health Development in Autism Spectrum Disorders
}

\author{
Irene E. Drmic, Peter Szatmari, and Fred Volkmar
}

\section{Introduction}

Health development results from dynamic personenvironment interactions that begin before conception and continue throughout the lifespan (Halfon et al. 2014; Russ et al. 2014). Life course health development (LCHD) incorporates theories and empirical evidence from the biological, physical, and social sciences to formulate a framework that explains how health develops over the life course. The principles of life course health development (see Halfon and Forrest 2017) describe health as an emergent set of capacities that develop continuously over the lifespan in complex, nonlinear processes that result from multilevel interactions of individuals and their environments. Furthermore, health is sensitive to the timing and social structuring of environmental exposures, as well as to timing and synchronization

\footnotetext{
I.E. Drmic $(\bowtie)$

Hospital for Sick Children, Toronto, ON, Canada e-mail: Irene.drmic@sickkids.ca

P. Szatmari

Centre for Addiction and Mental Health,

Hospital for Sick Children, University of Toronto,

Toronto, ON, Canada

e-mail: Peter.Szatmari@utoronto.ca

F. Volkmar

Child Study Center, Yale University School

of Medicine, New Haven, CT, USA

e-mail: Fred.Volkmar@yale.edu
}

of molecular, physiological, behavioral, social, and cultural functions. Finally, evolution enables and constrains the range of adaptive plastic responses and health developmental pathways associated with these phenotypes.

The life course health development conceptual framework can be applied to autism spectrum disorders (ASD) to help prioritize a research agenda and improve health development across the lifespan for individuals with ASD, their families, and communities. Novel approaches to understanding ASD are welcome given that ASD represents a major public health challenge. The estimated annual cost of caring for individuals with ASD in the USA is $\$ 137$ billion, with a lifetime cost per individual estimated to be $\$ 2.4$ million for those with co-occurring intellectual disability and \$1.4 million for those without intellectual disability (Dawson and Bernier 2013). The following chapter is not an exhaustive review of the literature in ASD; rather, we highlight some issues and findings that are pertinent to an understanding of ASD using the lens of the life course health development principles.

\subsection{What Is Autism Spectrum Disorder (ASD): The Clinical Phenotype}

Autism spectrum disorders are a group of neuropsychiatric conditions all of which share 
difficulties in social engagement and social interaction as their major diagnostic feature. As a result of this basic problem, difficulties arise in learning, cognitive organization, attention, and adaptive skills. Autism, the prototypic disorder, was described by Kanner in 1943 as an "inborn disturbance" of social contact. Autism was first included in a new category of pervasive developmental disorders when first recognized officially in the third edition of Diagnostic and Statistical Manual of Mental Disorders (DSM;APA 1980).

Autism is a condition of early onset and poses multiple problems in health development. Many parents are concerned about affected children's development by age 1 with the vast majority of parents worried by age 2 (Chawarska et al. 2008). An increasing body of work has focused on autism as it first develops in infancy (Rogers 2009). In a minority of cases (about 20\%), parents report some period of normal development followed by loss of skills; the clinical significance of regression continues to be debated (Parr et al. 2011; Shattuck et al. 2009).

Problems in social interaction are a hallmark of autism and related conditions. Social difficulties are distinctive even considering any associated developmental delays. Similarly, communication problems are present and persistent even in the more cognitively able children who lack verbal and nonverbal social communication skills such as gestures, facial expression, and eye contact. Even when children do speak, they exhibit a number of difficulties including echolalia, pronoun use difficulties, abnormal prosody, and in the social use of language (Paul 2008). Kanner noted the range of unusual behaviors frequent in autism including motor mannerisms (stereotyped movement), difficulties with change, and insistence on routines. The apparent over-engagement with the nonsocial world arises in the general lack of social engagement. This suggests a potential route both as a mechanism for learning difficulties and for intervention.

The original impression that autism was not associated with cognitive problems rested, in large part, on the unusual abilities of children in some areas; in some cases, these skills are highly circumscribed and may arise even in association with overall intellectual delay (Hermelin 2001).
Even for the most able individuals, scatter in abilities is often present with a relative deficit in verbal as opposed to perceptual abilities. It is also the case that there is frequently a gap between abilities in a formal testing situation and "realworld" or adaptive skills - the latter reflecting the significant difficulties individuals have in generalization and in tasks that involved fast-paced decision making, executive functioning, and social interaction (Robinson et al. 2009). In more classical autism, nonverbal skills tend to be much stronger than verbal abilities; the opposite profile may hold true for Asperger's disorder although this has been debated (Klin et al. 1996; Meyer and Minshew 2002; Noterdaeme et al. 2010).

As noted above in addition to classic autism of the type described by Kanner, a number of other conditions with some apparent similarity to autism have been recognized, although their validity apart from autism continues to be hotly debated. Asperger's disorder was described (Asperger 1944) the year after Kanner's report first appeared. Although the children (all boys) had major problems in social interaction, in contrast to Kanner's (1943) cases, they demonstrated good language abilities and were more likely to exhibit motor difficulties, unusual and allconsuming esoteric special interests, and their problems seemed to come to clinical attention rather later (Woodbury-Smith and Volkmar 2009). Although included in DSM-IV and International Statistical Classification of Diseases and Related Health Problems (ICD)-10 as a distinctive disorder, Asperger's disorder has been the focus of much debate and is not considered a diagnosable disorder in DSM-V.

A subthreshold pervasive developmental disorder category was included in DSM since 1980 to encompass individuals whose difficulties appear to fall close to autism but do not achieve thresholds for diagnosis of that, or related, conditions. Interestingly this concept also was described in the 1940s although not with great precision. It has as always been recognized to significantly outnumber more classical autism (Fombonne 2005a, b) by probably four or five times although research in this area has, paradoxically, been limited. In recent years, the tendency to equate pervasive developmental disorder not 
otherwise specified with more classic autism has led to a broader autism spectrum concept although it must be emphasized that the DSM-5 autism spectrum disorder concept would likely exclude many cases that in the past had been said to have pervasive developmental disorder not otherwise specified (Volkmar and McPartland 2014).

\section{$1.2 \quad$ Epidemiology}

It is clear that ASD has a strong genetic component and is likely related to the interaction of multiple genes (Devlin and Scherer 2012); ASD invariably originates in the first years of life. Poverty and lack of access to adequate resources and intervention clearly impact identification, service provision, and likely outcome (Liptak et al. 2008; Thomas et al. 2007), but this area of work remains one that is relatively little studied. Various factors complicate the study of prevalence rates in ASD. There has been a concern that rates have risen over time although in his review of the topic Fombonne (2005a, b) suggests that a median rate of strictly defined autism would be about 1 per 800 to 1000 people with the much broader pervasive developmental disorder category being much more common. Several recent studies have reported higher rates (e.g., Brugha et al. 2011; Elsabbagh et al. 2012), but studies of adults in community settings report similar rates to those estimated by Fombonne and others (Brugha et al. 2011; Elsabbagh et al. 2012; Rutter 1973) and various factors which might account for apparent increases in rates have been identified (King and Bearman 2009; Rutter 1982) with potential overestimation due to methodology (i.e., case-confirmation strategies) and small sample sizes resulting in high estimates (Levy et al. 2009). Such factors include increased public awareness and increased recognition of more cognitively able individuals, applying the diagnosis to individuals with specific syndromes such as Down syndrome and widening of diagnostic criteria, sundry methodological problems, and "diagnostic substitution" - the latter referring to an issue, particularly in the USA, where an edu- cational label of autism may be used to obtain services in preference to other labels such as mental retardation (Fombonne 2005a, b).

Most studies have reported significantly higher rates of ASD in boys than in girls although girls with more strictly defined autism are also more likely to have intellectual disability (Fombonne 2005a, b). The three- to fivefold increase in boys is similar to other neurodevelopmental disorders such as language disorders and attention deficit hyperactivity disorder (ADHD). It is possible that milder expression in some girls is underdiagnosed (Landa et al. 2007). There has been speculation that greater severity sometimes observed in girls is a function of a greater genetic risk for the condition (Fombonne 2005a, b) and that observed sex differences might relate to fundamental cognitive mechanisms (Baron-Cohen 2011). In reality, sex differences have been remarkably little studied and our understanding of this phenomenon remains very limited.

Potential social class correlates of autism first noted by Kanner (1943) in his original sample have not generally held up in subsequent research, presumably reflecting a referral bias in Kanner's original cases (Fombonne 2005a, b; Wing 1980). However, disparities in diagnosis rates are observed with children from backgrounds of poverty or minority status often going undiagnosed (LaFramboise et al. 2009). Although diagnostic presentation is rather similar around the world, cultural factors may impact both diagnosis and treatment (Brown and Rogers 2003).

\subsection{Classification and Diagnosis}

Several approaches were undertaken in the late 1970s to provide more operational definitions of autism. Rutter's approach (1978) emphasized difficulties in social interaction, communication, and unusual behaviors of early onset that were not solely attributable to mental retardation. Both family genetic and longitudinal studies provided important information on the stability and validity of the diagnosis apart from other conditions and led to the inclusion of autism in DSM-III (APA 1980). The DSM-III approach was modified 
in 1987 when DSM-III-R appeared and yet again with DSM-IV which appeared in 1994. The DSM-IV definition was based on results of a large international field trial and became consistent with the tenth revision of the ICD leading to two decades of diagnostic stability (Volkmar and McPartland 2014). For DSM-5, a number of changes were made and have proven controversial. The adoption of the term autism spectrum disorder seems well justified; however, the criteria proposed appear to really be more relevant to classic "Kanner's autism," and many individuals, particularly the more cognitively able, would likely lose their diagnosis (Volkmar and McPartland 2014). As a result, cases with "wellestablished" diagnosis of Asperger's or pervasive developmental disorder not otherwise specified (PDD-NOS; in DSM-IV terms) could retain an ASD diagnosis - thus effectively creating two diagnostic systems in current use; the advent of ICD-11 and the Research Domain Criteria (RDoC) approach suggest that for some time there may be considerable controversy about definitional issues (see Baker et al. 2012; Brand et al. 2012; Mattilla et al. 2011; McGrew et al. 2012; Watts 2012; Huerta et al. 2012).

\section{Pathogenesis}

\subsection{Hereditability}

ASD is now considered a disorder caused at least in part by genetic factors (Szatmari et al. 1998). The evidence for this comes from studies showing that ASD runs within families, from twin studies that show that this familial aggregation is due to genetic and possibly to shared environmental risk factors (Sullivan et al. 2012) and to the recent identification of several different networks of genes responsible for synaptic and axonal development and neuronal migration (Malhotra and Sebat 2012).

Early family studies looked at the recurrence risk to a sibling if one child in the family had ASD. Those sibling risks were around $2 \%$ which were considered to be very much higher than the general population rate estimated at that time to be 4 per 10,000 (Szatmari et al. 1998). With better study designs and with a better appreciation of the breadth of the ASD phenotype, these family studies now suggest that the risk to sibling is closer to 9\% (Ritvo et al. 1989). This needs to be seen in the context thought of more recent prevalence estimates of ASD of around 1\%. Thus, it seems the sibling recurrence risk is roughly ten times the population base rate (Constantino et al. 2010).

The baby sibs paradigm provides a more valid estimate of sibling recurrence risk. In these studies, the infant sibling of an older child with ASD is followed from birth to 3 years of age. In this context, the emergence of autistic signs and symptoms can be carefully documented prospectively, and the presence or absence of an ASD diagnosis is determined by 3 years of age. These studies have shown that signs and symptoms of the ASD phenotype begin to emerge around 6-12 months of age, and upward of $20 \%$ of siblings will have a diagnosis of ASD at 3 years of age (Chawarska et al. 2008; Zwaigenbaum et al. 2012). Interestingly, despite the fact that these studies have demonstrated that ASD can be diagnosed as early as 3 years and that best practice in ASD, such as the 2007 American Academy of Pediatrics guideline that all children should be screened for ASD at 18 and 24 months, the average age of diagnosis in the USA is still close to 5 years and higher in those with milder forms of ASD (CDC 2014).

Twin studies are used to determine the mechanism of familial aggregation. Earlier studies suggested very sharp discrepancies between monozygous and dizygous concordance rates suggesting not only that the mechanism of heritability was genetic but that there was little room for environmental risk factors in playing an important role in causation. The twin study with the largest sample size and the one carried out with the most methodological rigor was recently published (Hallmayer et al. 2011). In that study, monozygous concordance rates were closer to $60 \%$, and dizygous rates were $20 \%$ rate seen in the recent infant sibling studies. While the Hallmayer et al. twin study also provides support for the importance of genetic factors in 
the etiology of the disorder, the higher than expected dizygous concordance rate also suggests a significant role for shared environmental risk factors.

\subsection{Genetic Contribution}

Hundreds of different genes have been described in ASD that have been disrupted by either deletions or duplications of copy number. These genes all appear to be related to different aspects of neuronal development (largely synaptic functioning) or neuronal migration (Li et al. 2012). This is an important finding as it steers mechanisms of etiology away from neurotransmitters and monoamines, a theory which had dominated the field for several decades (McDougle et al. 2005).

With the discovery of copy number variants as important structural genomic risk factors for a variety of human diseases has come the realization that these variants might play an important role in the etiology of ASD (Marshall et al. 2008). Copy number variants represent deletions or duplications covering more than $1000 \mathrm{kbs}$ of DNA. In general, copy number variants can be common or rare, and they can be either de novo or inherited from parents. The first copy number variant identified in ASD in a genome-wide study was a rare deletion in the neurexin gene (Szatmari et al. 2007), and this has been followed up with many reports of other copy number variants affecting important brain-expressed genes (for a review see Malhotra and Sebat 2012). These copy number variants tend to be extremely rare, found in less than $1 \%$ of the ASD samples, and tend to rise de novo. This would explain the frequent lack of family history in ASD families and would provide a mechanism whereby the prevalence of the disorder remains stable in the context of a condition associated with reduced fertility (Power et al. 2012). Common genetic variants (either polymorphisms or copy number variants) have not been reliably identified in ASD, although such variants likely do exist and will require very large sample sizes for their identification (Devlin et al. 2011). If they do exist, their effect size must be very small or else they operate as modifying factors as opposed to susceptibility genes. Currently, copy number variants explain less than $10 \%$ of cases in ASD, and the population attributable risk is less than 5\% (Pinto et al. 2010). The etiology of the vast majority of cases of ASD remains to be explained. The next generation of genetic studies will focus on much smaller copy number variants or DNA sequence variants identified either in exomes or in whole genome sequencing.

\subsection{Nongenetic Contributions}

The search for environmental risk factors has been underway for many decades. There seems reasonably good evidence that certain maternal anticonvulsants such as carbamazepine, valproic acid, and perhaps other anticonvulsants increase risk for ASD (Palac and Meador 2011). Other putative environmental risk factors that may have been more common in earlier decades such as congenital rubella have now virtually disappeared. A complication in all this work is disentangling the sometimes complex issues of severe mental handicap and "autistic-like" behaviors, particularly since stereotyped mannerisms become much more common with severe intellectual deficiency, but characteristic socialcommunicative features may be either difficult to judge or not clearly present (Volkmar et al. 2005). Pregnancy and birth complications have been studied extensively, and other than low birth weight or being small for gestational age, it is difficult to identify a risk factor (see Gardener et al. 2009 for a recent meta-analysis). It should be noted, however, that low birth weight may in fact represent a consequence of genetic vulnerability rather than an environmental risk factor interacting with genetic susceptibility (Rutter 2005). Other potential environmental markers signaled by inflammatory indices are of interest but remain highly speculative at this point (Muller et al. 2015). Perhaps the most convincing evidence for an environmental risk factor is that of advanced parental age (Shelton et al. 2010). Since paternal and maternal age is so highly correlated, it is 
difficult to determine if both are risk factors or if only one. This is important as the mechanism by which the risk factor might operate will be quite different based on the maternal/paternal risk factor (Veltman and Brunner 2012). De novo copy number variants are more common with advanced paternal age, while chromosomal abnormalities (like trisomies) are more common with advanced maternal age.

\subsection{Epigenetic Contributions}

Epigenetic studies of non-syndromic ASD are in their infancy but do hold promise once technological and methodical issues associated with this area of study are resolved. Genes that regulate DNA methylation have been implicated in the etiology of ASD, and single gene disorders associated with ASD have implicated epigenetic mechanisms (Loke et al. 2015). It is anticipated that this will be an active field in the future and will yield novel insights in how personenvironment interactions lead to the development of ASD.

\subsection{Physical Biomarkers}

Magnetic resonance imaging and diffusion tensor imaging studies have provided some insight into brain structure, circuitry, and connectivity in ASD. Courchesne and colleagues followed toddlers from 12 months to 48 months and found an abnormal brain growth trajectory in autism (Schumann et al. 2010). Toddlers, who were ultimately diagnosed with ASD, showed enlargement of cerebral gray and white matter, which was most pronounced in the frontal, temporal, and cingulate cortices, and some gray matter regions showed an abnormal growth rate. In addition, in those infants who later developed ASD, there was a difference in the development of white matter tracks between 6 and 12 months of age (i.e., increases in fractional anisotropy), with a slowing in development by 24 months (Wolff et al. 2012). Thus, abnormal neurodevelopmental connectivity early in life could potentially serve as an important biomarker for ASD.

\subsection{Genotype-Phenotype Contributions}

In addition, genotype-phenotype correlations have been virtually impossible to establish, and the fact that the genetic variants identified in ASD also appear to be playing a role in intellectual disability, epilepsy, schizophrenia, and ADHD has emphasized the nonspecificity of these susceptibility risk factors (State 2010). These genetic findings in ASD have influenced healthcare recommendation and practice, such that microarray testing is part of the standard of care for diagnosis of ASD (McGrew et al. 2012). It is likely that in the future, whole exome sequencing will also become standard clinical practice. However, to date, no studies have directly assessed the impact of genetic testing on health outcomes such as earlier age of diagnosis or reduced use of other diagnostic tools such as MRI (Sun et al. 2015). In the future, we anticipate that there will be an increased application of genetics and neuroimaging to the early identification of ASD (Dawson and Bernier 2013). It is also likely that the discovery of genetic variants that impact the development of the synapse will lead to clinical trials of new (or "repurposed") drugs targeting those mechanisms. Such trials are already underway in fragile $\mathrm{X}$ and tuberous sclerosis but so far with disappointing results (Geschwind and State 2015).

\section{Outcome Studies}

\subsection{An Overview of Developmental Course}

Before reviewing approaches to assessing outcome, an overview of what is known, and what is not known, about the course of autism spectrum disorders may be helpful. It must be emphasized that outcome is usually very specifically defined as adult independence and that little information is available on health-related outcomes and vanishingly little relates to older individuals with ASD. Variations in life course are, in part, one of the rationales used to support previous diagnostic distinctions between subtypes. In more "classical" 
autism, it is clear that diagnosis in infancy is of great interest but also somewhat problematic until about age 3 when reasonable stability in clinical manifestations occurs. Before that time, the issue usually is between change from (or to) a more classic picture to a more "subthreshold" condition (an issue that may be mitigated by the broad approach adopted in DSM-5). Often the difficulty, using the DSM-IV, was that social and communication problems are present but the "restricted interests" criteria were not fully met (even though some likely precursor behaviors are present). Rarely a child moves off the autism spectrum entirely. There is good evidence (NRC 2001) that treatments are most effective when started early in life; although for reasons not well understood, some children do not improve as dramatically as others. It is important to emphasize that apart from a reasonably robust literature on adult outcome (i.e., early in adult life), the literature on adults with autism is very limited both in terms of actual numbers of studies and individuals studied and an absence of literature on the topic of aging in autism (Howlin 2013; Perkins and Berkman 2012). For example, few studies address the issue of rates of employment among adults with autism/ASD and rates of suicide or suicide attempts (even though depression is thought to be a frequent co-occurring condition), and no studies are available on the life course changes for individuals with autism/ ASD. Put another way (and viewed in the starkest possible light), it is as if adults with autism/ASD vanish from the scene once they've become adult and "had their outcome," such as capacities in young adulthood for personal independence and self-sufficiency.

School-age children with more "classic" autism often become more sociable as they get older, and gains in cognitive and communication skills also typically are made - sometimes dramatic ones and other times not. Social language use and peer relationships often remain areas of difficulties, and problems with agitation and selfstimulatory behavior may require behavioral or pharmacologic intervention. As first observed by Leo Kanner (Kanner 1971), in adolescence, some children make major gains, while another group unfortunately exhibits some degree of deterioration in functioning. A number of outcome studies now suggest a gradual change in overall prognosis presumably reflecting both earlier and better intervention as well as some changes in diagnostic practice over the time (i.e., including recognizing autism in more cognitively able individuals) (Howlin 2005). An increasing number of individuals are able to live independently and self-sufficiently as adults, and many now go to college or pursue technical/vocational training. Major predictors of adult outcome include level of intellectual functioning and communication competence. Some adults require intermediate levels of support, and in many cases, affected individuals never attain independence and must live in highly structured residential settings. Agerelated vulnerabilities have been noted, e.g., the risk of seizure disorder is substantially increased both in early childhood and again in adolescence and possibly well into adulthood. More able adults with autism and related conditions also are apparently more vulnerable to anxiety and depression which can require specific treatments (Howlin 2013; Skokauskas and Gallagher 2010; Szatmari and McConnell 2011; White et al. 2009).

Data on outcome in Asperger's disorder are, expectedly, less extensive but suggest (also as might be expected) overall better outcomes in terms of independence, educational attainment, employment, and social independence. However, comorbid conditions, such as anxiety and depression, can be a complicating factors and negatively impact outcomes (Skokauskas and Gallagher 2010; Szatmari and McConnell 2011; White et al. 2009; Volkmar et al. 2014). There is some suggestion of increased risk for both psychosis and legal difficulties in adolescence and adulthood, but the evidence for this consists largely of case reports (Skokauskas and Gallagher 2010; Szatmari and McConnell 2011; White et al. 2009).

Studies of children with "subthreshold" pervasive developmental disorder are very uncommon although, on balance, these individuals appear to have a better outcome than those with more classical autism (Towbin 2005). The outcome in childhood disintegrative disorder and Rett's does appear, unfortunately, to be poor (Volkmar et al. 2005; Van Acker et al. 2005). In childhood disintegrative disorder, children lose 
skills but then plateau and make relatively minimal gains. In Rett's, the course is well known with children becoming somewhat more sociable over time but also more incapacitated due to neurological and movement problems.

\subsection{Adult Independence}

Information on long-term prognosis is limited and difficult to interpret. This review will focus primarily on long-term follow-up outcome studies that have been published over the past decade (for reviews of earlier outcome studies see Gillberg 1991; Henninger and Taylor 2012; Howlin 2000; Howlin and Moss 2012; Levy and Perry 2011; Nordin and Gillberg 1998). The majority of studies that report on "outcomes" for people with ASD have focused on a few domains (e.g., work status, residential situation, friendships; see more detailed discussion below). Predicting outcome has been difficult due to the wide variability in cognitive, linguistic, social, and behavioral abilities in this group of individuals. Consistent interpretation of different findings has also been difficult due to varied sample size (generally small), sampling procedures (clinical versus population based), differences in diagnostic criteria over time, wide range of age at diagnosis, differences in amount of time between initial and follow-up assessments, differences in measures used, imprecise and/or poor quality data on early intellectual functioning, and the lack of information about early intervention services. These factors may account, in part, for the substantial variability reported in adult outcomes for people with ASD.

As noted previously, although psychosocial outcomes have generally been poor, there is a trend over time for higher rates of improvement (see Table 1 - description of how the outcome categories were defined is provided below; Beadle-Brown et al. 2002; Billstedt et al. 2005, 2007, 2011; Eaves and Ho 2008; Farley et al. 2009; Gillberg 1991; Hofvander et al. 2009; Howlin 1998; Howlin et al. 2004; Kobayashi et al. 1992; Lockyer and Rutter 1969, 1970; Lotter 1978; Lovaas 1987; Nordin and Gillberg
1998; Rutter et al. 1967; Rutter and Lockyer 1967; Szatmari et al. 1989). Studies conducted from the 1950 s to 1970 s reported that less than $15 \%$ of individuals had good/very good outcomes and the majority had poor/very poor outcomes (Eisenberg 1956; Rutter et al. 1967; Lotter 1974). Over the past three decades, outcomes have improved but remain variable; the proportion of good to very good outcomes ranges from $4 \%$ to $62 \%$ and poor to very poor outcome ranges from $3 \%$ to $78 \%$ (see Table 1). Outcomes have been classified into different outcome categories ranging from "very poor to very good" by various studies over the years. Of note, these ratings were more subjective in earlier studies (pre-2000), whereas more objective criteria have been used in recent studies (for a detailed discussion, see Henniger and Taylor 2012).

The group of studies published within the last decade used quantifiable outcome criteria to classify individuals with ASD into these different outcome categories ranging from very poor to very good (see Howlin et al. 2004, Appendix 2, for detailed criteria). In general, the criteria used to determine outcome were based on a 5-point composite rating of overall social and independent living functioning that was derived by summing individual scores for work status (ranging from $0=$ employed or self-employed to $3=$ no occupation), residential situation (ranging from $0=$ living independently to $5=$ being in hospital care or at home because nowhere else would accept the individual), and number and quality of meaningful friendships (ranging from $0=$ more than one friendship to $3=$ no friendships or joint activities) . Based on the 5-point composite rating, a score of 0 indicated a "very good" outcome (i.e., total for all three areas between 0 and 2); $1=$ "good" outcome (total 3-4); 2 = "fair" outcome (total 5-7); 3 = "poor" outcome (total $8-10$ ); and 4 = "very poor" outcome (total 11). Thus, the concept of "outcome" is related to practical independence and autonomy achieved in adult life.

Howlin and her colleagues (2004) surveyed 68 adults (average age of 29 years) with autism who had a performance IQ of 50 or above in childhood and found that the majority (58\%) had 


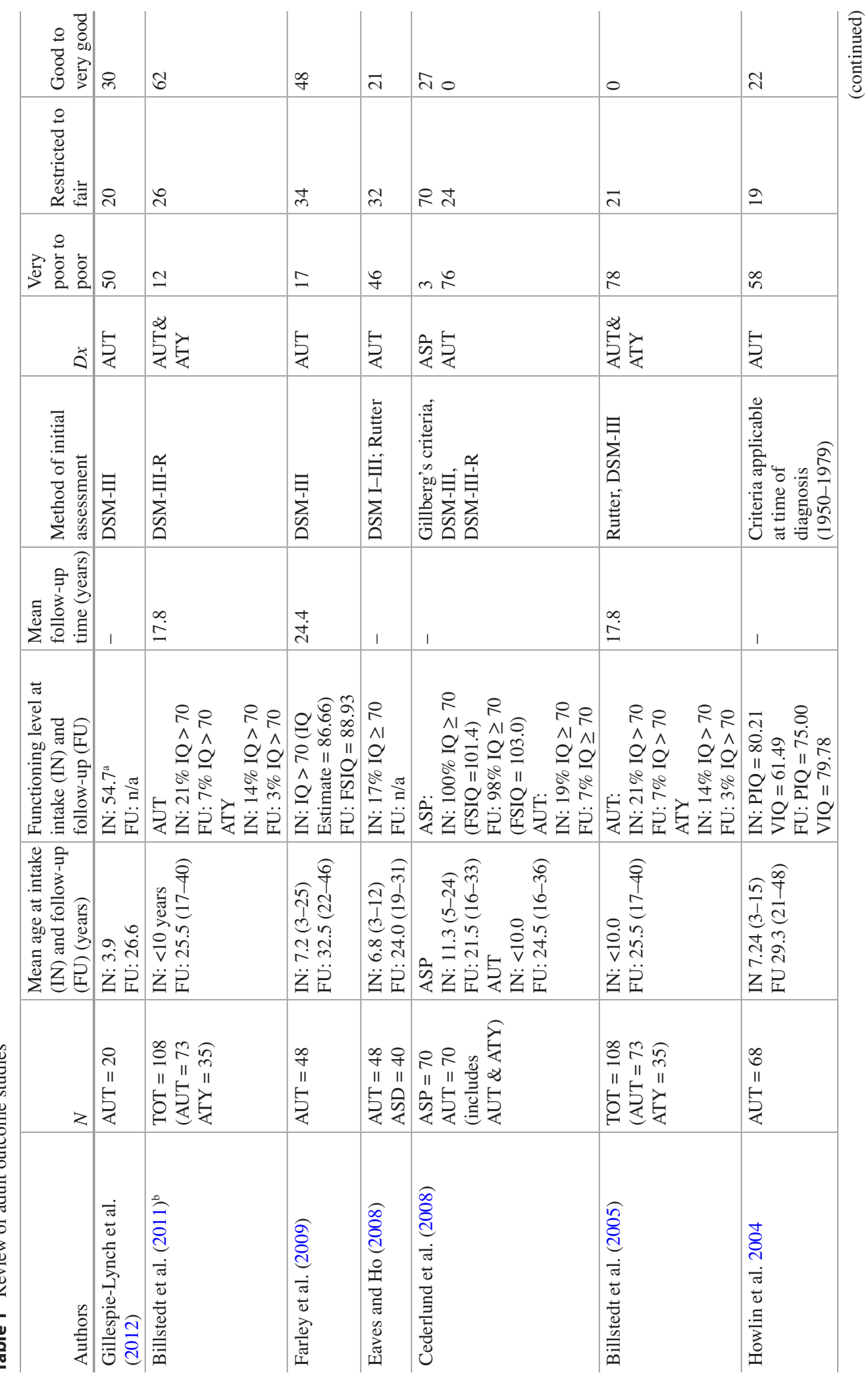




\begin{tabular}{|c|c|c|c|c|c|c|c|c|c|c|}
\hline $\begin{array}{ll} & \overrightarrow{0} \\
8 & 0 \\
0 & 0 \\
0 & 0 \\
0 & 0 \\
0 & 0\end{array}$ & $\simeq$ & $\stackrel{0}{0}$ & m & 0 & $\hat{\imath}$ & t & 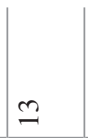 & \pm & in & \\
\hline 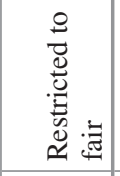 & 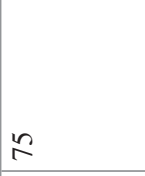 & 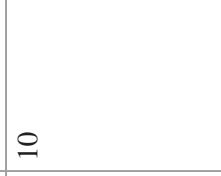 & 壮 & 0 & $\hat{\imath}$ & $\stackrel{\infty}{9}$ & ป & 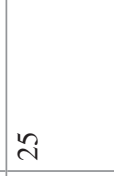 & ส & \\
\hline 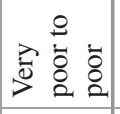 & $\simeq$ & 咅 & สิ & 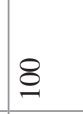 & fo & 导 & 8 & $\overline{6}$ & $\stackrel{M}{2}$ & \\
\hline 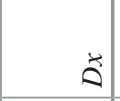 & 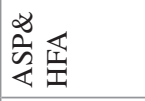 & 飠 & 苍安 & 客 & 娄 & 客 & 点 & $\Leftrightarrow$ & 炱 & \\
\hline 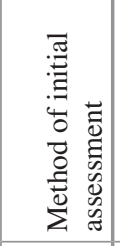 & $\sum_{n=1}^{1}$ & 离 & 官 & 站 & $\begin{array}{l}\stackrel{0}{1} \\
\sum_{\tilde{n}}^{1} \\
0\end{array}$ & 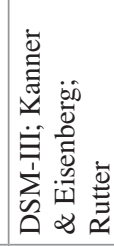 & 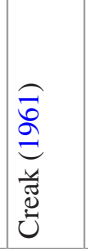 & 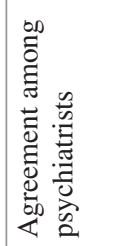 & $\begin{array}{l}\ddot{\Xi} \\
\frac{\tilde{\omega}}{\tilde{g}} \\
\underline{5}\end{array}$ & $\begin{array}{l}\frac{n}{0} \\
\frac{0}{0} \\
\frac{0}{0}\end{array}$ \\
\hline 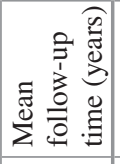 & 1 & 1 & లి & $\begin{array}{l}0 \\
\infty\end{array}$ & 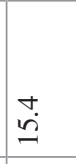 & $\vec{\jmath}$ & $\infty$ & $\hat{a}$ & a & 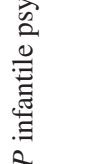 \\
\hline 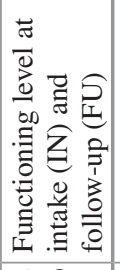 & 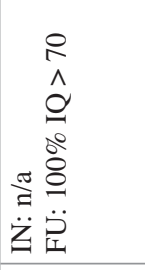 & 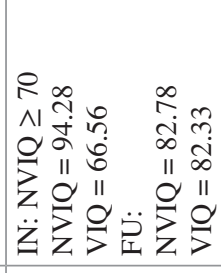 & 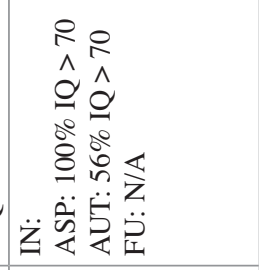 & 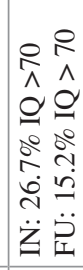 & 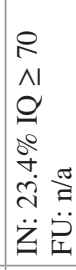 & 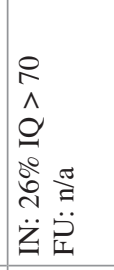 & 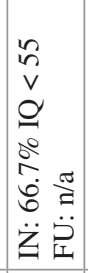 & 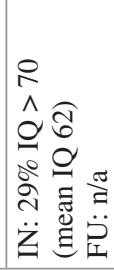 & $\stackrel{\pi}{\Xi}$ & 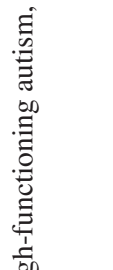 \\
\hline 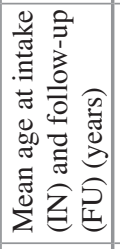 & 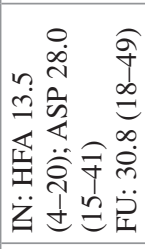 & 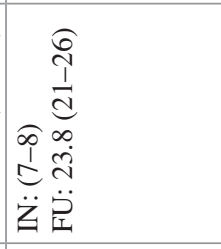 & 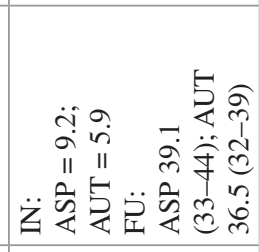 & 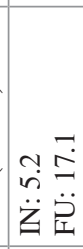 & 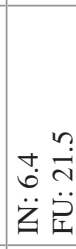 & 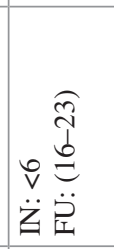 & 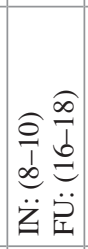 & 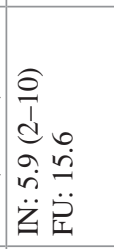 & $\begin{array}{ll}0 & n \\
\ddot{z} & \ddot{2} \\
\end{array}$ & 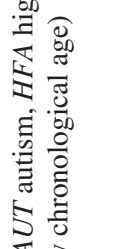 \\
\hline$z$ & 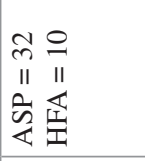 & $\begin{array}{l}2 \\
11 \\
5 \\
8\end{array}$ & \begin{tabular}{ll}
$a$ & $a$ \\
II & $\| 1$ \\
5 & 2 \\
2 & \multirow{2}{*}{}
\end{tabular} & $\begin{array}{l}0 \\
11 \\
11 \\
5 \\
8 \\
8\end{array}$ & $\begin{array}{c}\overrightarrow{8} \\
\text { 1I } \\
11 \\
5 \\
2\end{array}$ & $\begin{array}{l}2 \\
⿱ 1 \\
11 \\
-5 \\
2 \\
2\end{array}$ & $\begin{array}{l}2 \\
\text { II } \\
11 \\
5 \\
2\end{array}$ & $\begin{array}{l}n \\
\text { II } \\
\cong\end{array}$ & $\begin{array}{l}3 \\
11 \\
5 \\
3 \\
2\end{array}$ & 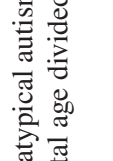 \\
\hline 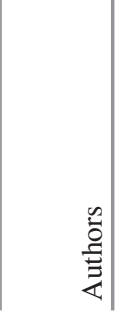 & 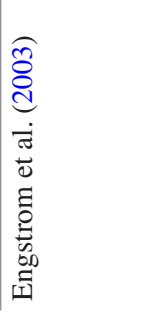 & 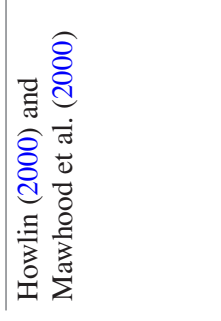 & 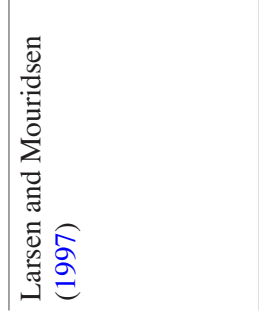 & 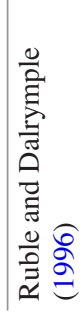 & 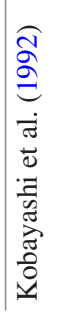 & 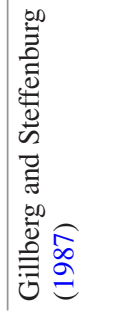 & 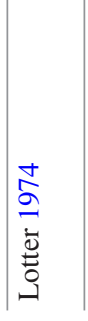 & 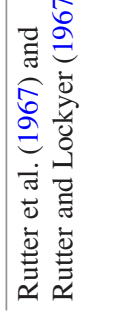 & 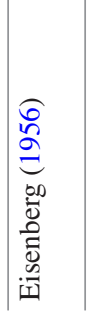 & 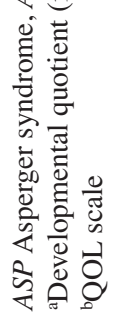 \\
\hline
\end{tabular}


poor or very poor outcomes, $19 \%$ had fair outcome, and $22 \%$ had good or very good outcome. Those individuals with a performance IQ of at least 70 in childhood had significantly better outcome than those with an IQ below 70. More specifically, of those individuals with a performance IQ between 50 and $69(n=23)$, only one individual had very good outcome, three were rated as fair, and the remaining had poor or very poor outcome. Individuals in this IQ category had much poorer prognosis with few having jobs, friends, or achieving independence as adults. In the group of individuals with near average to average IQ, outcome was generally better, although still quite variable. Of those individuals with an IQ of 70 or above $(n=45$; parental data missing on one individual), 14 individuals were rated as good or very good, 10 as fair, and 20 as poor or very poor. Furthermore, there was no difference in outcome in those individuals with an IQ over 100 and those with and initial IQ between 70 and 99. Interestingly, many individuals with an IQ between 70 and 99 made better progress in terms of academics, jobs, and general level of functioning, than those with an IQ above 100. Thus, having an IQ of about 70 seemed to be a critical cutoff point for better outcome (e.g., level of independence); however, outcome in these individuals was still quite variable.

Other studies found a similar pattern of results. Billstedt et al. (2005) examined a group of lowto middle-functioning individuals $(82 \%$ had an IQ below 70) with autism or atypical autism and found that $91 \%$ had poor or very poor outcome and none were reported to have good outcome. Eaves and Ho (2008) reported somewhat better outcomes in a group of low-to middle-functioning individuals (majority had IQ $<70$ ) with approximately half having fair to good outcome and half poor (but none very poor). Similar outcomes were reported by Gillespie-Lynch et al. (2012), with 50\% reporting poor outcome and $50 \%$ fair to very good outcome. Engstrom, Ekstrom, and Emilsson (2003) reported on the psychosocial functioning of a systematically selected sample of patients with Asperger syndrome (AS) and high-functioning autism (HFA) all of whom had an IQ above 70 . The majority were rated as hav- ing a fair outcome (75\%), with few being rated as good or poor (12\% each) and none being rated as very poor. Farley et al. (2009) also examined adult outcomes for 41 individuals with average or near average cognitive abilities and found better outcomes compared to the other studies with $48 \%$ showing good or very good outcome, $34 \%$ with fair outcome, and only $17 \%$ with poor outcome (none with very poor outcome). Taken together, these studies suggest that outcomes for adults may be improving and that this is likely related to availability of services for individuals with ASD (Gillespie-Lynch et al. 2012; Kobayashi et al. 1992). However, it is important to also take into consideration the pattern of attrition in longitudinal studies. For instance, selective attrition of lower functioning individuals may account for the more positive outcomes in some studies (Eaves and Ho 2008; GillespieLynch et al. 2012).

\subsection{Quality of Life}

Although the vast majority of studies have based outcomes on level of independence achieved in adulthood and IQ, symptom severity and language development are thought to be important factors in these outcomes; there is increasing interest in examining outcomes based on quality of life (QOL) indictors. QOL is a more comprehensive and multidimensional concept that also encompasses one's subjective evaluations of their experiences (Burgess and Gutstein 2007). According to the World Health Organization (WHO), the concept of QOL not only includes level of independence and social relationships but also is composed of the person's health, personal beliefs, and their relationship to salient features of their environment (Saxena and Orley 1997).

Generally, studies show that overall QOL and health-related QOL is relatively low for people with ASD (Kamp-Becker et al. 2011; van Heijst and Geurts 2015; Potvin et al. 2015). van Heijst and Geurts (2015) conducted a meta-analysis on QOL studies that included children, adolescents, and adults with ASD and found that QOL is 
lower in people with ASD compared to people without ASD and age did not have an effect. The lack of association with age has previously been reported (Kamino et al. 2012; Kamp-Becker et al. 2011), although it had also been reported that increasing age is associated with decreasing quality of life (Bennett et al. 2005). Characteristics that were relevant predictors in the traditional adult outcome studies, including symptom severity, IQ, and early language, were not examined because information was too sparse. Given the dearth of information about the elderly, the authors also conducted an empirical study examining QOL in intellectually able elderly individuals with ASD and again found large difference in QOL in people with versus without ASD with lower QOL in individuals with ASD. Interestingly, age, IQ, and symptom severity did not predict QOL in the elderly.

Billstedt et al. (2011) examined aspects of quality of life (QOL) in adults diagnosed with autism or atypical autism in childhood and found that the majority of the ASD group remained dependent on parents for support in education, recreation, and occupational situations in late adolescents and early adulthood, but QOL was quite positive (independent of intellectual functioning). The QOL scale used in this study measured both objective and subjective (although by proxy) indicators of well-being. The authors who evaluated the participants completed a QOL scale assessing "autism-friendly environment" using a five-item scale (QOL-1). The item categories were (1) staff and caregivers have specific "autism knowledge," (2) applied structured education implemented, (3) individual specific treatment/training plan for the person with autism implemented, (4) occupation or everyday life activity corresponding to his/her level of capacity, and (5) overall quality of life. Each item was rated on a 1 (very good) to 5 (very poor). A second QOL scale assessing "parent/care rating of individual's well-being" was obtained to estimate how the individual with autism enjoyed or liked his/her residential conditions (QOL-2). Sixtytwo percent of individuals were rated as having a very good or good QOL by the authors (QOL-1), and $91 \%$ of families reported high or very high residential well-being (QOL-2). This is consistent with reports among young adults with intellectual disabilities who reported satisfaction with their lives even though they remained quite dependent on caregivers (Keogh et al. 2004) and a greater sense of empowerment than those individuals who were still in the school system (Kraemer et al. 2003). Howlin (2013) emphasized that traditional definitions of "good outcome" or "independent living" may not be the most suitable goal to strive for individuals with ASD, because it may lead to a life with little support that is isolated and lacking in stimulation. More research examining QOL is needed in ASD. Raphael et al. (1996) conceptualize a QOL model, which is relevant to persons with developmental disabilities, as containing three domains that include "being, belonging, and becoming" (p. 28). The "being" domain includes being who one is or wants to become, "belonging" includes how one fits within their environment, and "becoming" involves pursuit of personal goals and wants. They also noted that within each domain, it is important to consider the perceived importance, enjoyment experienced, perceived control, and opportunities for change and enhancement. Thus, it is important to also examine and understand the subjective experience of the individuals with ASD and their families when assessing outcome. As with any chronic disability, having a condition like ASD may predispose to other problems - particularly difficulties with depression and anxiety disorder; the relative dearth of work on adult outcome and complexities of the problems of comorbidity and diagnosis limit our understanding of the developmental pathways that result in these outcomes. Similarly, even for the most cognitively able adults (e.g., those who attend college), challenges remain in various areas including adaptive (realworld) skills and generalization, social interaction, organization abilities, and so forth (Farley et al. 2009). As noted previously, the significant limitations of the available literature must be emphasized - issues of QOL have not frequently been assessed, even more cognitively able individuals may lead lives of social isolation with comorbid mental health conditions, medication 
use is quite high, limitations in daily life can result from poor adaptive skills, and essentially no information is available on aging (Howlin 2013). Thus, given the large differences between quality of life in people with and without ASD, a great deal of work needs to be done to understand how to support optimal health development in individuals with ASD and provide their families with the kinds of interventions that will enable them to achieve a higher QOL and promote wellbeing. A shift in research focus is needed to understand factors that lead to a better QOL across the life course. There is some evidence indicating that a higher QOL is related to earlier diagnosis (Kamino et al. 2012), greater perceived support (Renty and Roeyers 2006), and supported employment, residential, and leisure programs (Garcia-Villamisar et al. 2002, García-Villamisar and Dattilo 2010; Gerber et al. 2011). Thus, considerable work is needed to improve QOL in people with ASD, and a better understanding of the developmental trajectory across the lifespan may help to better understand the need and interventions required to support these individuals.

\subsection{Predictors of Adult Independence}

Intellectual functioning (IQ) and language have been most consistently identified as the best predictor of adult personal independence as outcome in ASD (Billstedt et al. 2005, 2007; Gillberg and Steffenburg 1987; Gillespie-Lynch et al. 2012; Howlin et al. 2004; Kobayashi et al. 1992; Lotter 1974; Nordin and Gillberg 1998; Rumsey et al. 1985), although reports have been variable (Farley et al. 2009; Gillespie-Lynch et al. 2012). Farley et al. (2009) reported that early childhood variables were weakly associated with adult outcomes, but the participants in their study all had communicative phrase speech or better language by age 6 and near average to average IQ. GillespieLynch et al. (2012) also found that early intellectual functioning did not predict adult outcomes but suggested that this may be because the average age of the first assessment was quite young (mean age of 3.9 years). Cognitive testing of chil- dren with autism older than 4-5 years of age is reported to give more stable measures than in those children who are tested at younger ages (Lord and Schopler 1989; Howlin et al. 2004). In general, however, the presence of an intellectual disability (ID) is associated with poorer outcome in people with ASD in adult life (Cederlund et al. 2008; Gillberg and Steffenberg 1987; Howlin et al. 2004; Rumsey et al. 1985; Shattuck et al. 2007), with the poorest outcomes for those individuals with an IQ below 50 (Lord and Bailey 2002). Few people with this level of cognitive impairment (IQ < 50), regardless of an ASD diagnosis, achieve a high level of independence as adults (Keogh et al. 2004; Kraemer and Blacher 2001). Conversely, higher levels of intellectual functioning (IQ > 70) are associated with better outcome (Billstedt et al. 2007; Eaves and Ho 2008; Gillberg and Steffenberg 1987; Howlin et al. 2004; Rumsey et al. 1985; Szatmari et al. 1989), but outcome can still be quite variable in these individuals (Billstedt et al. 2005; Howlin et al. 2004). These data further underscore the importance of focusing on early language development and learning (IQ) in early intervention programs for children with ASD.

With regard to verbal and performance (nonverbal) IQ, the results are more inconsistent. Some have reported that childhood verbal IQ is a better predictor of later functioning than performance IQ (Billstedt et al. 2005; Lord and Bailey 2002), whereas another study found neither to be a consistent prognostic indicator (Howlin et al. 2004). In addition, the presence of good early language skills before age 5-6 is crucial for positive outcome in ASD (Billstedt et al. 2007; Gillberg and Steffenberg 1987; Gillespie-Lynch et al. 2012; Lockyer and Rutter 1969; Lotter 1978; Szatmari et al. 2003). Mawhood et al. (2000) have shown that individuals who tended to have better linguistic outcome in adulthood were functioning at a higher cognitive level more generally.

Other factors have also been suggested to be related to outcome, including symptom severity, repetitive/stereotyped behaviors in childhood, adaptive behavior, education, gender, the presence of a diagnosed medical disorder, onset of 
epilepsy before age 5 years, and joint attention skills (Billstedt et al. 2007; De Meyer et al. 1973; Farley et al. 2009; Gillespie-Lynch et al. 2012; Howlin and Goode 1998; Totsika et al. 2010; Venter et al. 1992). For instance, Farley et al. (2009) reported that adaptive behavior measures (in particular the Daily Living Skills domain) evaluated at follow-up were most closely correlated to better outcomes. They described a group of individuals with a high IQ but poor practical living skills who felt frustrated by these limitations. Furthermore, they also described individuals who had a low IQ but who were able to manage with little assistance and obtained good or very good outcome rating despite poor cognitive skills. These results have important implications for intervention programs that foster these practical living skills in adulthood.

The development of joint attention skills may be another important area to target in early intervention programs because of the relationship of this developmental skill set with later health development outcomes. Joint attention skills typically develop between 6 and 18 months of age and refer to ability of the infant to coordinate their attention with another individual during a social interaction. Joint attention skills are important because they are considered early markers of social cognitive development; that is, they reflect the early development of the infant's ability to think about the perspective of another individual (Tomasello 1995). These skills are critical to social learning and social information processing (Mundy and Jarrold 2010), language development (Sigman and Kasari 1995), and the emergence of social and behavioral competence in childhood (Vaughan Van Hecke et al. 2007). Children with ASD present with deficits in joint attention regardless of their developmental or intellectual level, and these deficits are neither absolute nor uniform (Mundy et al. 2009).

In a recent longitudinal study into adult outcomes, responsiveness to joint attention, but not initiation of joint attention (IJA), was found to predict later outcomes. Responsiveness to joint attention was found to predict gains in IQ from early childhood ( $M=3.9$ years) to later childhood $(M=11.7$ years $)$ and receptive language in late adolescents/early adulthood $(M=18.3$ years $)$ (Sigman and McGovern 2005; Sigman and Ruskin 1999). In terms of adult outcomes, responsiveness to joint attention predicted adult nonverbal communication, social skills, and symptoms (Gillespie-Lynch et al. 2012). In addition, responsiveness to joint attention and early language both predicted a composite measure of adult social functioning and independence. Taken together, responsiveness to joint attention measured in early childhood may reflect early emerging social cognition, and preliminary evidence suggests that it may be a good predictor of social behaviors in adulthood. Gillespie-Lynch and colleagues also suggested examining the relationship with responsiveness to joint attention and early executive functioning in childhood on later outcomes given that executive functioning is related to adaptive functioning in children with autism (Gilotty et al. 2012).

Gulsrud et al. (2014) examined the developmental trajectories of specific joint attention gestures (i.e., pointing, showing, coordinated joint looking) and expressive language over a 6-year period and found that coordinated joint looking and showing increased over time and pointing to share interest increased over the preschool years (3-5 years of age) and then decreased. They also reported a causal relationship between early pointing and later language development; that is, those children with high rates of pointing in the preschool years had better expressive language skills later. Hence, an understanding of the developmental course of joint attention skills allows for better consideration deciding "when" to intervene. Based on the data, the authors suggested that it may be useful to focus on pointing in early childhood when the child is preverbal and less useful when the child begins to use spoken language. Thus, the interval when early joint attention skills develop may represent a critical or sensitive period to intervene and potentially impact the developmental trajectory and outcomes for individuals with ASD. In addition, the children who received the joint attention intervention showed the fastest improvement compared to the control condition or child who received a different intervention. Participation in 
the joint attention treatment placed these children on a different developmental trajectory. This highlights that "what" you target and "when" you intervene are important (Gulsrud et al. 2014).

\subsection{Diagnostic Stability and Symptom Severity}

There is considerable debate in the literature regarding the stability of a diagnosis of autism and other forms of ASD over time. Some studies report that individuals diagnosed in childhood continue to meet criteria for the disorder at follow-up (Billstedt et al. 2005; Cederlund et al. 2008; Howlin et al. 2004; Lotter 1978); whereas others report a change in diagnosis or movement "off" the spectrum in some individuals (Daniels et al. 2011; Kleinman et al. 2008; Turner and Stone 2007). Two recent studies reported that a diagnosis of autism was reasonably stable, whereas for other forms of ASD such as pervasive developmental disorder, the results were more variable (Rondeau et al. 2011; Woolfenden et al. 2012). Rondeau et al. (2011) did a metaanalysis on eight longitudinal studies, published between 1996 and 2009, examining autism and pervasive developmental disorder. All diagnoses were made before 36 months of age, and the interval between the initial and follow-up assessment was short, ranging from 12 to 84 months. They reported that an autism diagnosis tended to be a more stable than pervasive developmental disorder. Of those with pervasive developmental disorder, only $35 \%$ retained the same diagnosis (versus the $76 \%$ reported for autism), $39 \%$ moved to autism, and $25 \%$ moved off the spectrum. The authors concluded that those children diagnosed with pervasive developmental disorder at a young age should be reassessed at an older age.

The diagnosis of autism is relatively reliable and stable over time. Issues arise for very young children (the full syndrome picture sufficient for diagnosis may not be observed until age 3 years) and for individuals with "autistic-like" or "spectrum" conditions not so clearly satisfying strict diagnostic criteria. For example, Woolfenden et al. (2012) conducted a systematic review of 23 longitudinal studies (many overlapping with Rondeau et al. 2011) examining the stability of the diagnosis of children initially diagnosed with autism and other forms of ASD. The mean age of children at baseline ranged from 1.8 to 11.3 years, and mean duration at follow-up ranged from 2.1 to 32.5 years. Overall, autism was found to be a stable diagnosis although lower estimates (as low as 53\%) were reported for children diagnosed in the preschool years (below 3 years of age). A small percentage of individuals diagnosed with autism, between $12 \%$ and $15 \%$, move off the spectrum altogether. For other ASD's (including pervasive developmental disorder, Asperger's disorder, but not autism), based on the highest quality studies, the pattern of stability was more variable with $14-61 \%$ retaining their initial diagnosis at follow-up. A few studies reported on optimal outcome in autism (Fein group), and while these adults are indeed quite independent and functional, it appears that some autistic traits remain.

Taken together, a diagnosis of autism is more stable than the other ASD subtypes such as pervasive developmental disorder (Rondeau et al. 2011; Woolfenden et al. 2012), which is consistent with the rationale for the DSM-5 (Szatmari 2011). Given that the ASD category is less stable due to the inclusion of pervasive developmental disorder individuals, this presents challenges to clinicians when sharing a diagnosis of ASD with parents in terms of making appropriate intervention recommendations (Woolfenden et al. 2012).

Impairments in the core ASD symptoms (impairment in communication, reciprocal social interaction, and repetitive or stereotyped behaviors and interests) also tend to persist into adulthood (Billstedt et al. 2007; Howlin 2003; Matson et al. 2008), although symptom severity is reported to decrease in some individuals over time (Seltzer et al. 2003; Shattuck et al. 2007). Totsika et al. (2010) found that an older (50 years or older) group of adults with ASD and ID presented with fewer behavioral problems than the younger $(<50$ years) group, which is consistent with reports of decreases in behavior problems in the general adult intellectual disability population (Holden and Gitlesen 2006). Billstedt et al. 
(2007) found that social interaction problems were still present in the vast majority of adults with ASD, but the occurrence of behavioral impairments (maladaptive and stereotyped behaviors) was much more variable with only a few symptoms in each category affecting half or more of the study sample. Others have reported that behavioral problems continue into the adult years (Ballaban-Gil et al. 1996) and that unusual responses to sensory (e.g., touch, pain, auditory, and visual) stimuli also remain common in adulthood (Billstedt et al. 2007; Leekam et al. 2006).

\subsection{Cognitive Stability}

There is considerable variability in measures of cognitive ability over time. Some have reported that IQ is relatively stable in ASD (e.g., BallabanGil et al. 1996; Begovac et al. 2009; Howlin et al. 2004; Lockyer and Rutter 1970; Venter et al. 1992), whereas others have reported gains and/or losses over time (Billstedt et al. 2005; Farley et al. 2009; Mawhood et al. 2000). Howlin and colleagues reported that IQ remained remarkably stable over the life course; however, stability tended to be greatest among individuals with an initial IQ of at least 70. On the other hand, Billstedt et al. (2005) found that many individuals who initially had near average intelligence (IQ between 71 and 85) were later diagnosed with a mild (IQ 50-70) or severe (IQ < 50) intellectual disability, and those individuals with a severe intellectual disability $(\mathrm{IQ}<50)$ in the original diagnostic study were all still in this category at follow-up. Overall, they found a downward shift of IQ level from the diagnostic study to the follow-up evaluation. A decrease in IQ may be an important biological marker in a subset of individuals with ASD (Farley et al. 2009). Farley et al. (2009) reported that over half of the sample had either large gains or losses in cognitive ability of greater than 1 standard deviation. Cognitive gain was associated with better outcome, as was better adaptive functioning. Some of the variability in results may be, in part, accounted for by the way IQ was measured or assessed, the age of initial assessment (IQ less stable in young children), and level of functioning of the participant, and the sometimes highly varied cognitive profiles of individuals which may evolve over time. This variability in IQ trajectory may also be due to the cumulative or time-specific impact of other risk or protective factors on the plasticity of IQ development.

\section{Transitions Over the Life Course}

\subsection{Childhood}

Children with ASD, like all other children, undergo several transitions throughout their school years. For instance, this may include the transition from early intervention to preschool, changing grades each year and moving into adolescence and then into adult life. Individuals with ASD also struggle with smaller transitions that are required on a daily basis, such as transitioning from one context to another. For example, this may include a transition between classes or transitions to unfamiliar settings (e.g., doctor's office). It is important to plan for these transitions because ineffective transition planning can have a negative impact on social and academic progress (Adreon and Stella 2001). Thus, numerous studies have emphasized the importance of transition planning for all children with special needs (Polloway et al. 2001), and this is particularly significant for children with ASD who frequently struggle with transitions. The ease with which a child transitions depends on the strategies adopted by educators when working with the child with ASD and their family (Harris and Handelman 2000). Parents of young children with ASD identified a number of factors that support successful and effective transitions, such as good communication between the school and home, transition plans that are child-centered, and inclusion of parents (Stoner et al. 2007).

Longitudinal studies of ASD have emphasized documenting the prevalence of certain outcomes (such as the stability of the diagnosis) rather than a more detailed look at developmentally related changes over time. Some studies are now taking 
a life course health development perspective by focusing on trajectories (Kim et al. 2015). The Pathways in ASD study, for example, followed roughly 400 children from the point of diagnosis at 2-4 years of age to the transition into primary school at 6 years of age allowing for the possibility of heterogeneous trajectories of autism symptoms and adaptive functioning. The results suggested (Szatmari et al. 2015) that heterogeneity in the rate of change of both phenotypes occurred, with some children doing remarkably well in adaptive function, but autism symptom severity remained more stable. There was little overlap of the autistic symptom severity and adaptive functioning developmental trajectories so that the course of the two seemed relatively independent, thereby highlighting the importance of close surveillance and treatment of these two domains independently over time because improvement in one area does not ensure improvement in the other area. These data also suggested that at least for the transition into primary school, continued improvement is possible for the majority of children with ASD.

A growing evidence base suggests that behavioral interventions can be associated with positive outcomes for children with ASD, with little evidence and generally poor quality studies available in adolescents and adults (Lounds Taylor et al. 2012; Weitlauf et al. 2014; National ASD Center National Standards Project 2009, 2015). Early interventions that were based on highintensity applied behavior analysis over extended periods of time were associated with improvements in cognitive functioning and language skills, although the magnitude of effects varied across studies (Weitlauf et al. 2014). This variability may be related to the scarcity of information about modifying factors related to subgroups (Weitlauf et al. 2014). For instance, the majority of evidence supports the efficacy of comprehensive early intensive behavioral interventions (EIBI), which is currently the standard of care in many clinics and schools (Peters-Scheffer et al. 2011; Reichow 2012). Meaningful gains have been shown in IQ, language skills, and adaptive outcomes with medium to large effects (Reichow 2012; Strauss et al. 2013) and a decrease in autism severity over time (Zachor and Itzchak 2010). Gains are not universal, some making rapid progress and others only modest or no progress (Peters-Scheffer et al. 2011; Reichow and Wolery 2009). Inclusion of parents in skill generalization has led to overall higher effect sizes (Strauss et al. 2013). Early intensive parent programs have been shown to modify parent behavior during interactions, but there is less data about their ability to improve developmental skills beyond language gains for some children (Weitlauf et al. 2014). Predictors of positive outcome and/or changes in trajectory include younger age at entry into EIBI programs (between 18 months and 5 years), higher IQ or adaptive functioning or language (mild to moderate range of functioning), and less severe autism symptoms (Strauss et al. 2013). With regard to program characteristics, intensity of EIBI programs was related to gains in IQ, adaptive functioning, and language ability, whereas duration of the program was generally not related to gains with the exception of some evidence that it was related to language and adaptive behavior gains (Strauss et al. 2013). Contemporary early intervention ABA approaches are more naturalistic, childdirected, and guided by developmental theory and are currently referred to as naturalistic developmental behavioral interventions (NDBI's) (for detailed discussion see Schreibman et al. 2015). Other behavioral interventions that have shown some positive effects include, but are not limited to, social skills, treatment targeting joint attention, and cognitive behavior therapy (Weitlauf et al. 2014). Research is beginning to show that behaviorally based interventions have an effect on patterns of brain activity, particularly in regions involved in social processing (Dawson et al. 2012), and that neural plasticity in response to intervention may exist throughout the lifespan (Faja et al. 2012).

Thus, the evidence supports that early interventions are effective in ASD; however, less is known about how sustainable these intervention effects are after transitions from early intervention into preschool and elementary school. There is emerging evidence that young children with ASD who received early intervention sustained 
social, language, and/or nonverbal cognitive gains through a 6-37-month follow-up period (e.g., Kasari et al. 2010; Landa et al. 2011; Landa and Kalb 2012). For instance, Landa and Kalb (2012) examined outcomes in 2-year-old toddlers enrolled in a 6-month nursery school-based intervention immediately following intervention (M age $=35$ months $)$, at short-term $(\mathrm{M}$ age $=41$ months $)$ and long-term follow-up (M age $=72$ months; 37 months after children completed intervention). At long-term follow-up, they found gains in IQ and communication; however, increases were not evenly distributed across the different time points. Gains in IQ and communication were robust initially from pre- to post-intervention, followed by a period of stabilization, which was then followed by another developmental burst. In contrast, the trajectory of autism severity was different with an initial decrease in severity form pre- to post-intervention, followed by an increase in severity to preintervention levels by the final time point. Magiati et al. (2011) reassessed outcomes even later at 5 years after departing preschool and found that children maintained standardized IQ scores, but adaptive functioning scores decreased. Longerterm outcome studies are needed to determine the sustainability of gains, as well as to determine whether there are sensitive periods in development as well as the developmental scaffolding that is necessary, especially during key life course transitions that are likely to promote optimal health development outcomes (e.g., age, type of intervention, duration, intensity, content, etc.) (Landa and Kalb 2012).

\subsection{Transition from Adolescence into Adulthood}

For youth with ASD and their families, the transition into adulthood is a time of uncertainty and loss of entitlement to many services that were available while in the school system. In comparison to early childhood, there often is a dearth of appropriate supports and opportunities for adults with ASD. Leaving high school can have a disruptive effect on youth and young adults with
ASD in a number of areas, including ASD symptom presentation, maladaptive behaviors, and family functioning (Taylor and Seltzer 2010, 2011a, b). Taylor and Seltzer (2010) examined the impact of exiting high school and observed that in general, autism symptoms and maladaptive behaviors continued to improve while adolescents were part of the secondary school system, but improvement significantly slowed (by over half) after exiting high school for internalizing behavior and all but one of the autism symptom domains (i.e., verbal communication impairments). The authors suggested that this change was likely related to the lack of disabilityrelated services or that occupational or day program services were less stimulating than those in the school system. Interestingly, youth without comorbid intellectual disability improved more in both autism symptoms and maladaptive behaviors while in high school compared to those with intellectual disability (Shattuck et al. 2007), but after exiting high school, improvement slowed more for those individuals without an ID (Taylor and Seltzer 2010). Indeed, only $6 \%$ of individuals with ASD without comorbid ID were receiving day services immediately after high school, compared to $74 \%$ with ASD and ID, and over one-quarter had no occupational, educational, or day activities. In addition, the improvement in the mother-youth relationship seen in high school slowed or stopped after high school (i.e., decreasing maternal warmth), with the greatest impact on relationships for youth with ASD and no ID (Taylor and Seltzer 2011a). Thus, leaving high school had a negative impact on individuals with ASD, with the most pronounced effect on those youth with ASD without an ID, suggesting a particular lack of adequate educational and occupational activities for this group of individuals in adulthood. It also highlights that individuals with ASD and no ID are often impaired in their adaptive skills and encounter difficulty generalizing these skills in daily life. When services are inadequate, parents will often take on this responsibility, leading some families to experience this transition period as a time of stress and anxiety (Howlin 2005). Other families view this period as an opportunity 
for new and more positive possibilities, such as finding more appropriate occupational placements and leaving high school, which for some youth, was a negative experience (Taylor 2009).

Access to autism-related services is also related to family income. Families with lower incomes and less parental education may have less access to autism-related services in childhood compared to families with higher incomes (Liptak et al. 2008; Thomas et al. 2007). Improvement in maladaptive behaviors slows after high school more so for those families with a lower income (Taylor and Seltzer 2011b). Thus, it is important to better understand the factors that promote optimal transition for individuals with ASD, as well as the impact on families. Taylor (2009) underscores the importance of examining contextual and environmental factors that are amenable to change or can be targeted in intervention in order to improve success with transition and suggests that exclusively focusing on characteristics such as IQ and early language that although are predictive of later outcome is more difficult to intervene once the individual with ASD becomes an adolescent or adult. For instance, the implementation of transition planning has been associated with more successful achievement of adult milestones (Frank and Siltington 2000). Indeed, factors such as the posthigh school goals for the student and parental expectations were predictive of participation in postsecondary education (Chiang et al. 2012). In addition, the development of appropriate educational, occupational, and day programs for individuals with ASD of all ability levels is important as is a lifelong emphasis on generalization of skills.

\subsubsection{Educational Attainment}

With regard to education, many individuals in the follow-up studies published in the last decade attended specialized schools or classrooms (Billstedt et al. 2011; Farley et al. 2009, Howlin et al. 2004). Only a few individuals with ASD obtained formal qualifications (Eaves and Ho 2008; Howlin et al. 2004), although results of recent studies have been more promising (Hofvander et al. 2009; Farley 2009). For example,
Farley and colleagues reported that $44 \%$ completed high school at grade 12 with a diploma, and $39 \%$ went on to postsecondary education. With regard to those students who are capable of entry into college or university, many do not seek or gain entry or drop out prematurely (Glennon 2001; VanBergeijk et al. 2008) due to a number of factors including social isolation and loneliness, difficulty managing changing routines and schedules, difficulty with independent living, and the absence of monitoring and guidance (Howlin et al. 2004; Jobe and White 2007; White et al. 2011).

Students with ASD are able to succeed both academically and socially in postsecondary education when the transition is carefully planned, appropriate accommodations are obtained, and supports are available (for detailed discussion, see VanBergeijk et al. 2008). Preparing students for the transition to postsecondary education is important for many adolescents but is particularly important for individuals with ASD, most of whom have difficulty with transitions. VanBergeijk and colleagues stress the importance of a good fit between the student and the prospective academic institution. For instance, this may include careful consideration of the size of the school and classes, level of supports, and receptiveness to serving students with disabilities specifically ASD, access to mental health services, and availability of supports to address both academic concerns (e.g., organizational help, accommodations related to evaluation and test taking, support with complex assignments, etc.), as well as nonacademic concerns including life skills, issues of daily living (e.g., laundry, budgeting), organizational difficulties, communication limitations, and social skills (e.g., socializing with peers, getting along with roommates, romantic relationships). Indeed, adolescents with ASD reported greater concern about social acceptance and being able to function independently than about accessing academic accommodations and resources in postsecondary educational settings, and thereby identified a need for built in social supports and access to trained staff members as a resource (Camarena and Sarigiani 2009). Many individuals with ASD also have difficulty with issues related to sexuality and may 
require support or direct instruction (see Volkmar 2004). Furthermore, postsecondary educational programs must also include planning and preparation for the transition to work and independent living that includes vocational training and life coaching (VanBergeijk et al. 2008). Families and educators are also encouraged to support the development of self-advocacy skills which are important to the transition process so that adolescent and young adults are able to navigate the journey through higher education, work, and independent living (Camarena and Sarigiani 2009). Thus, for students with aspirations for postsecondary education, careful planning and supports are required to help students with ASD achieve academic success.

\subsubsection{Employment, Independent Living, and Social Life}

The research on transition into adulthood in individuals with ASD has primarily focused on the traditional view of transition which describes the degree of independence in living arrangements, ability to gain and maintain employment, and the presence of intimate relationships outside of the family unit (Fussell and Furstenberg 2005). The majority of individuals with ASD have difficulty achieving the developmental tasks of adulthood and remain dependent on parents/caregivers for support in employment and accommodation, and most do not have intimate relationships (friendship or romantic).

Many persons with ASD are able to work successfully within the community (GarciaVillamisar et al. 2000; Mawhood and Howlin 1999); however, the majority experience difficulty securing meaningful employment (Billstedt et al. 2011; Eaves and Ho 2008; Howlin et al. 2004; Newman et al. 2011). Findings from the National Longitudinal Transition Study-2 (NLTS2) examined a nationally representative sample of youth and young adults with disabilities in the USA and found that up to 8 years posthigh school, only $63 \%$ of adults with autism had worked at some point after high school and only $37 \%$ were employed at the time of the survey (Newman et al. 2011). In a group of individuals with near average to average intelligence, the outcomes were somewhat more promising with $54 \%$ in full-time or part-time independent paid jobs, $12 \%$ in supported employment or part-time volunteer positions, $24 \%$ in day programs, and $10 \%$ unemployed (Farley et al. 2009). Even among those who are employed, many worked few hours, and most jobs tended to be low level, were found by parental contacts (versus open job market), and were poorly paid such that individuals did not have adequate financial support to live independently (Cimera and Cowan 2009; Eaves and Ho 2008; Howlin et al. 2004). Furthermore, many individuals were in part-time, volunteer, supported, or sheltered employment; few worked independently with little or no support, and some had no daytime occupation at all. Jobs often ended prematurely because of social or behavioral difficulties or other work-related difficulties (Mawhood and Howlin 1999). Cimera and Cowan (2009) examined cost of services and employment outcomes achieved by adults with ASD in the vocational rehabilitation system. The study found that adults with autism were employed at higher rates than other disability groups; however, the rate of employment was only $41 \%$ (60\% do not obtain employment), and as noted earlier, they worked fewer hours and earned lower wages. Adults with autism were also the most costly group of individual to serve, and services were difficult to implement. Howlin (2013) underscores that generic employment services do not meet the needs of individuals with ASD, and there is a need for more programs and research specific to individuals with ASD. Although limited, research is beginning to emerge showing that supported employment models for individuals with ASD are effective (Howlin et al. 2005; Keel et al. 1997; Shattuck et al. 2012; Taylor et al. 2012).

Critical factors in finding and maintaining a long-term placement include a thorough assessment to appropriately match the skills and abilities of the person with ASD to the requirements of the job, as well as having the appropriate level and type of employment support (Mawhood and Howlin 1999; Smith and Paulippen 1999). 
Hagner and Cooney (2005) found that a set of supervisory accommodation strategies were commonly associated with successful supervision, including maintaining a consistent schedule and set of job responsibilities, using organizers to structure the job, minimizing unstructured or idle time, being direct with communication, and providing reminders and reassurances. Longer job retention has been correlated with higher levels of social inclusion and acceptance on the job (Belcher and Smith 1994). Furthermore, engaging in work is often related to other meaningful outcomes, such as contributing to one's selfworth and confidence, providing opportunities to shares one's strengths that are valued by others, opportunities to develop friendships or other supportive relationships, as well as engagement in the larger community (Lee and Carter 2012). On the other hand, failure to find suitable work resulted in frustration and in some serious problems with depression and/or anxiety (Mawhood and Howlin 1999). With supported employment, individuals with ASD are able to find and maintain suitable employment (Mawhood and Howlin 1999).

Most individuals with ASD live with their parents or in other supported arrangements (e.g., community-based group home), and few live independently either with or without some level of support (Billstedt et al. 2011; Farley et al. 2009). Eaves and Ho (2008) reported that 56\% lived with their parents, $35 \%$ were in supported arrangements such as group homes or foster care, and the remainder lived more or less independently. With regard to friendship, it has been reported that up to approximately $30 \%$ of individuals have one or more friends (Eaves and Ho 2008; Howlin et al. 2004). Social contacts often result from special interests and skills rather than close friendships (Howlin 2000). Some individuals have been reported to want friendships but were unable to form these relationships, whereas others had no interest or did not understand the concept of friendship (Billstedt et al. 2011). Few individuals had close intimate relationships or were married at some point (Eaves and Ho 2008; Farley et al. 2009; Hofvander et al. 2009; Howlin et al. 2004). In a group of higher functioning individuals with ASD, Farley and colleagues reported that $7 \%$ were married, $5 \%$ divorced, $7 \%$ were in long-term relationships, $44 \%$ never dated, $32 \%$ dated in both group and couple situations, and $22 \%$ dated only in group settings. When parents were asked whether they felt their adult child wished to have a romantic relationship, of those participants not already in relationships, $44 \%$ felt their son or daughter would like to be in a relationship. On the other hand, $41 \%$ did not want a romantic partner because parents thought their children were concerned about passing on autism to a child or themselves being too difficult for a partner to manage.

\subsubsection{Summary}

Taken together, the research to date focuses primarily on the attainment of traditional skills that are indicative of successful transition into adulthood and less on more subjective or quality of life indicators. Although outcomes are quite variable, in general, outcomes related to level of independence, employment status, and intimate relationships are poor, suggesting that the transition to adulthood is fraught with many challenges. Evidence suggests that better outcomes are related to better cognitive abilities and earlier language skills, although even these individuals struggle with attaining the developmental tasks of adulthood. Furthermore, availability of appropriate resources, services, and supports for the individuals with ASD and their families are key ingredients for successful transition into adulthood and better outcomes throughout adult life. Lee and Carter (2012) identified seven elements that are important for high-quality transition services, which include individualized services that reflect the strengths of the individual, positive career development and early work experiences, collaboration and interagency involvement, family supports and expectations, fostering self-determination and independence, social- and employment-related skill instruction, and establishment of job-related supports. Thus, the impetus of future research is to examine factors that will support successful transition (e.g., environmental and contextual factors) 
and find other ways to define transition such as from a psychosocial or attachment perspective (for review, see Taylor 2009), especially as the epidemiology of ASD changes from autism with ID to a preponderance of ASD without ID.

\subsection{Aging and ASD}

Autism is a lifelong condition; however, little is known about older adults with ASD. Indeed, much of the research to date has examined the aging ASD population but not the aged ( 65 plus) (Perkins and Berkman 2012). Although information is quite limited, research suggests that life expectancy is shortened compared to the general population and causes of death include high rates of seizures and accidental deaths (e.g., drowning) (Mouridsen et al. 2008; Piven and Rabins 2011). It is unclear whether deaths that are related to diseases (e.g., nervous and sensory disease) in ASD are due to a predisposition to certain health concerns or due to poor health surveillance leading to poor diagnosis and management (Perkins and Berkman 2012). A number of medical and psychiatric concerns have been reported in children and adolescents with ASD, such as sleep disorders, psychiatric symptoms, gastrointestinal disorders, feeding selectivity and aversions, metabolic conditions, and epilepsy; however, there is little information about these concerns as individuals age (Piven and Rabins 2011). Similarly, it is unclear whether treatments that are effective in children and adolescents would also benefit adults. Given the dearth of information of older adults with ASD, a group of experts were convened to characterize the gaps in knowledge and define a research agenda to bridge this gap (see Piven and Rabins 2011). Research priorities included developing diagnostic criteria and tools to diagnose older adults, conducting cross-sectional descriptive studies in adults of phenomenology and associated features, longitudinal studies of lifespan trajectories, neurobiological studies examining underlying changes over time, intervention studies, and mechanism to support clinical and research training in aging. This research is needed to improve the lives of individuals with ASD and to inform clinical practice and policies that can address these healthcare disparities (Piven and Rabins 2011).

\section{Mental Health Issues in ASD}

\subsection{Prevalence Rates}

In terms of quality of adult life, there is increasing evidence suggesting that comorbid psychiatric symptoms and disorders are common in individuals with ASD, with estimated rates ranging from $30 \%$ to $70 \%$ (e.g., Bradley et al. 2004; Gjevik et al. 2011; Leyfer et al. 2006; Moseley et al. 2011; Simonoff et al. 2008; Skokauskas and Gallagher 2010). Understanding comorbid mental health problems is important not only because of the high prevalence but also because of the impact on daily functioning, long-term prognosis, and the added burden and challenges faced by individuals and their families. Individuals with ASD have higher rates of comorbidity compared to the general population (Ghaziuddin et al. 1998; Moseley et al. 2011), a psychiatrically referred population of youth without ASD (Joshi et al. 2010), as well as individuals with ID alone (Bradley et al. 2004; Brereton et al. 2006; LoVullo and Matson 2009), although the latter has not been consistently found (Tsakanikos et al. 2006). The most commonly reported psychiatric disorders include anxiety and depression (MacNeil et al. 2009; Sterling et al. 2008; White et al. 2009). ASD has also been found to co-occur with obsessive compulsive disorder (OCD), disruptive behavioral disorders, attention deficit hyperactivity disorder (ADHD), bipolar disorder, Tourette's disorder, tic disorder, and eating disorders (Drmic amd Szatmari 2014; Skokauskas and Gallagher 2010; Szatmari and McConnell 2011; Volkmar et al. 2014; White et al. 2009). Studies examining schizophrenia have been mixed; some studies report high rates (Chang et al. 2003), whereas others have not found an increased rate (Seltzer et al. 2004; Volkmar and Cohen 1991). Although the two disorders are quite different, misclassification of ASD as schizophrenia may also contribute to the variability in reported rates (Perlman 2000; 
Palucka, Bradley, Lunsky 2008). Furthermore, ASD often co-occurs with multiple psychiatric disorders (Leyfer et al. 2006; Simonoff et al. 2008). For instance, Simonoff et al. (2008), using a population-based cohort, conducted a structured psychiatric interview (not modified for ASD) with $11210-14$-year olds and found that $70 \%$ of ASD participants had at least one comorbid disorder and $41 \%$ had two or more. It is important to better understand this comorbidity given that many individuals with ASD are likely to struggle with mental health concerns, and more importantly, psychiatric problems may cause considerable distress and interference with daily functioning and significantly impact long-term prognosis and outcome (Kim et al. 2000; Mattila et al. 2010; Muris et al. 1998; Russell and Sofronoff 2005; White et al. 2009)

To date, the majority of research on psychiatric comorbidity has been conducted in children and adolescents (Amr et al. 2012; Gjevik et al. 2011; Leyfer et al. 2006; Mattila et al. 2010; Skokauskas and Gallagher 2010). In a review conducted by Skokauskas and Gallagher (2010) examining comorbid disorders in children with autism and Asperger syndrome, wide ranges in rates of co-occurring symptoms or diagnoses were found: $0-6 \%$ for schizophrenia, $5-35 \%$ for generalized anxiety, 10-64\% for simple phobias, $1-37 \%$ for OCD, and $0-50 \%$ for affective disorders or symptoms. Fewer studies have examined this issue in adults, although research in this area is beginning to emerge (Cederlund et al. 2010; Ghaziuddin and Zafar 2008; Hofvander et al. 2009; La Malfa et al. 2007; Lugnegard et al. 2011; Moseley et al. 2011), and a number of follow-up studies have reported on psychiatric outcomes (Billstedt et al. 2005; Eaves and Ho 2008; Farley et al. 2009). A study that examined young adults with Asperger syndrome found high rates of depression and anxiety, consistent with the literature in children and adolescents with ASD, whereas psychotic and substance-induced disorders were uncommon (Lugnegard et al. 2011). Hofvander et al. (2009) assessed 122 consecutively referred adults with ASD and normal intelligence ranging in age from 16 to 60 years. Lifetime axis I comorbidity was common, and they also found that mood (53\%) and anxiety disorders $(50 \%)$ were most common, followed by ADHD (43\%), OCD (34\%), and chronic tic disorders $(20 \%)$. With regard to the rate of lifetime axis II disorders, $62 \%$ met criteria for at least one personality disorder. Other studies have reported somewhat lower rates of anxiety (Farley et al. 2009; Moseley et al. 2011) and depression (Billstedt et al. 2005; Eaves and Ho 2008; Farley et al. 2009; Moseley et al. 2011). A study examining adolescents and young adults with autism (over three-quarters had an intellectual disability) found that $42 \%$ had an additional mental health disorder, a rate that is two to four times seen in typically developing young people (Moseley et al. 2011). There is some evidence that the rates of mood and anxiety disorders in parents of children with autism is higher than that in the general population and when compared to Down syndrome (Bolton et al. 1998; Mazefsky et al. 2008). This may reflect an effect of stress on family members. A more thorough examination of genetic variable expressivity would involve a study of mood disorders in second- and thirddegree relatives.

\subsection{Mental Health Services}

Given the high rate of psychiatric comorbidity, there is a need for appropriate mental health services for individuals with ASD of all ages. This includes preventive interventions designed to optimize mental functioning and life course trajectories. In a study investigating the healthcare experiences of children with ASD and their families, it was found that $15 \%$ of families reported unmet mental health services, and provider lack of skills was a barrier to obtaining these services (Chiri and Warfield 2012). With regard to the utilization of mental health services by individuals with ASD, the reports are mixed, with some reporting underutilization of services (Bryson et al. 2008) and others reporting relatively high rates of service use (Narendorf et al. 2011). Narendorf et al. (2011) reported that of those youth who received mental health services (i.e., $46 \%$ ), $49 \%$ received it through the school. 
African-American youth and youth from lowerincome families were more likely to use schoolbased services than accessing community-based services, underscoring the importance of schools in providing these services for underserved group and the importance of ensuring the continuation of services after high school. For students with ASD, there is emerging research examining the delivery of mental health services in schools for anxiety (Drmic, Aljunied, Reaven 2017; Luxford, Hadwin, Kovshoff 2016). Bryson et al. (2008) found that short-term crisis-oriented mental health services were effective at stabilizing children with ASD but that many remained highly symptomatic at discharge, suggesting that changes are needed to the current system in order to serve those individuals with chronic and long-term needs.

Many individuals with ASD may be at risk for psychiatric hospitalization. Indeed, approximately $11 \%$ of children and youth aged 5-21 years experienced at least one psychiatric hospital inpatient admission (Mandell 2008), and $48 \%$ used psychiatric hospital services by age 40 (Mouridsen et al. 2008). Children with a diagnosis of Asperger's disorder and pervasive developmental disorder, compared to children with autism, were more likely to experience inpatient hospitalization (Bryson et al. 2008). Lunsky et al. (2009) compared patients with ASD and ID to other individuals accessing tertiary level mental healthcare in Ontario and found that individuals with ASD and ID were younger, spent more days in hospitals, and were less likely to have a psychotic disorder diagnosis than both patients with and without ID. Interestingly, fewer than half of the individuals with ASD and ID had an additional psychiatric diagnosis, although almost all (91\%) were prescribed psychotropic medication, which is consistent with previous studies (Tsakanikos et al. 2006, 2007a). Tsakanikos et al. (2007b) reported that behavioral management problems predicted psychotropic medication and use of psychiatric services in adults with pervasive developmental disorder and ID. A study examining referral trends to specialist mental health services in south London from 1983 to 2000 for individuals with ASD and ID reported an increase in diagnosable psychiatric disorders over time and a significant reduction of medication at time of referral, but no change in the use of other therapeutic interventions, which is in contrast to services received by younger children with ASD. Thus, there continues to be a need for specialized inpatient and outpatient mental health services for individuals with ASD, as well as more training for service providers.

\section{Summary}

ASD is a neurodevelopmental disorder that represents a chronic, lifelong condition based on atypicalities in brain development. While there are changes in syndrome expression over time, new challenges often emerge. Much of the current research has focused on static or crosssectional outcomes as opposed to developmental trajectories and changes in those trajectories. This can include looking at the developmental course of the disorder, the developmental course of specific skills that are important to later outcomes such as joint attention skills, as well as trajectories, related to the effects of early intervention. Longer-term studies are critical to treatment research in order to determine the sustainability of early intervention treatment gains, to explore whether there are sensitive periods of child development when treatments are most effective, and to determine factors that promote treatment outcome. Research needs to include enough information about factors that might be important to outcome so that predictors can be better elucidated, as well as a shift to focus on mediators and moderators of outcome. There is a need for more longitudinal studies and some consensus about the type of information that should be gathered by all research groups so that findings are comparable among different studies and can be combined into meta-analyses. For instance, standardized IQ measures could be used to document intellectual abilities. It may be beneficial to convene a group of experts as well as parents and individuals with ASD to determine what basic set of factors are important.

The current review highlights that outcomes for people with ASD have been improving over 
time; although relative to typically developing children and adolescents, outcomes are still generally poor. Much of the work to date has focused on achieving the traditional developmental tasks of adulthood, including independence in living arrangements, gaining and maintaining employment, and developing intimate relationships outside of the family unit. Research examining quality of life is beginning to emerge, which is an important next step to further our understanding of how to help improve the lived experiences of individuals with ASD. QOL studies need to shift focus and include information about factors and developmental processes that are thought to be important to achieving better life course health development outcomes, such as IQ, symptom severity, and language development. In addition, examining other factors that promote thriving in individuals with ASD is needed. Understanding what those factors are is critical so that better programs and interventions can be developed, which include the developmental scaffolding that children and families need to optimize longterm health development outcomes. It is also important to understand what impact access to adequate resources and intervention has on the identification, service provision, and likely outcomes on people with ASD. Another key theme is the development and emergence of mental health comorbidities which often represent an enormous challenge for young adults with ASD and their families. Research needs to include information about the developmental pathways that lead to these outcomes so that risk and protective factors can be targeted early, with the intent of optimizing the trajectory of mental health outcomes. There is also a need for more basic research such as epigenetic studies of nonsyndromic ASD, genetic studies that focus on much smaller copy number variants or DNA sequence variants identified either in exomes or in whole genome sequencing, and continued research examining environmental risk factors.

A number of recommendations to facilitate the transition periods and support individual with ASD and their families can be gleaned from the existing literature. Implementation of a transition plan is crucial since it is associated with more successful transition from early intervention into preschool (Stoner et al. 2007) and attainment of adult milestones (Frank and Siltington 2000) and may help temper the disruptive effect of leaving high school (Taylor and Seltzer 2010, 2011a, b). Parents, clinicians, and educators are encouraged to begin the transition planning process for the transition to adulthood early and include planning for treatment, independence (i.e., daily living skills, skills for independent living), education, employment, living arrangements, mental health, and medical care. For instance, good practical living skills, even in those individuals who have a cognitive disability, led to better outcomes and quality of life (Farley et al. 2009). Therefore, focusing on developing independence in daily living skills starting from a young age is an important target for intervention programs and transition planning. This highlights the importance of planning early so that skills can be integrated into treatment and educational programs at younger ages, allowing for ample practice and supervision of these skills well before the individual is expected to be able to manage on their own.

For many individuals and families, the transition to adulthood is a time of worry and uncertainty because many services that were available through the educational system are no longer available and there are few appropriate supports or services for adults with ASD. Taylor and Seltzer (2010) showed that the improvement slowed significantly after exiting high school, particularly for those youth with ASD and no ID. This change was likely related to a lack of services or that available services were less stimulating than those provided in the educational system. Thus, the development of new models of care that incorporate appropriate educational, occupational and day programs for adults with ASD of all ability levels is essential. However, simply having a program is not enough; it is also important to ensure that the appropriate training and support is provided on an ongoing basis to the individual with ASD and that service providers are adequately trained to work with this group of individuals. For instance, given the prevalence and impact of mental health issues in individuals with ASD and their 
families, there is a need for ongoing mental health services and staff who are trained in this area and able to support families. A worrying trend is the increased use of psychopharmacology in adults with ASD often as a result of lack of psychosocial services that might better meet those needs in a way that improves life course outcomes and promotes thriving. Another example relates to successfully obtaining and maintaining long-term employment, which may involve supportive employment programs that include training related to general job skills (e.g., resume writing, interviewing skills, proper social behavior), specific skills needed for a particular job (e.g., learning job requirements and skills, learning about the culture and expectations for that job), and ongoing support (e.g., job coach). Training and support should also be provided to the employers in order to educate them about ASD in general, help them understand the needs of a particular individual, as well as highlight their unique skills and abilities that can positively contribute to workplace. Indeed, parents, educators, employers, and other professionals are encouraged to appreciate the many strengths, skills, and unique talents of individuals with ASD and approach current programs and future planning from a strength-based approach, leveraging each individual's unique set of assets, versus a deficits-based approach that focuses on what needs to be fixed.

There is a stark lack of information about ASD in the aging and elderly population. Given this gap in knowledge, a group of experts were convened to identify and describe these gaps and define a research agenda (see Piven and Rabins 2011). The research proprieties included developing diagnostic criteria and tools to diagnose older adults, conducting cross-sectional descriptive studies in adults of phenomenology and associated features, longitudinal studies of lifespan trajectories, neurobiological studies examining underlying changes over time, and intervention studies and mechanism to support clinical and research training in aging.

This change in perspective might be part of a shift from treatment of deficits to accommodation of unique characteristics of the adult with ASD. There comes a time when the relentless pursuit of treatment to "make things better" will have a negative impact on the person with ASD and their family. People with ASD should not always be considered "disabled," and taking a lifespan perspective to developmental trajectories should be part of this switch for service providers as well as parents.

\section{Research Priorities}

There has been a marked increase in ASD-related research over the past decades. Considerable advances have been made in key areas, including: the genetic basis of ASD and its diagnosis; studies of the social brain; the connections between timing of diagnosis and long-term outcomes; new treatment models, some pharmacological and behavioral treatments can now be viewed as evidence based; psychiatric co-morbidities with particular emphasis on anxiety and depression; and, research on basic issues like employment, living arrangements, medical survelillance, etc. Thus, a number of gaps remain that need to be addressed. The following summarizes a number of recommendations for research, some of which were noted earlier in the paper, to better understand life course health development in ASD.

\subsection{Research Priorities}

(i) Basic mechanism research:

(a) Better understanding of epigenetic mechanisms in non-syndromic ASD.

(b) Continued research in the area of genetics and neuroimaging. For example, this could include:

- Genetic studies that focus on much smaller copy number variants or DNA sequence variants identified either in exomes or in whole genome sequencing

- Studies that assess the impact of genetic testing (e.g., microarrays) on health outcomes

- Studies combining genetics and neuroimaging work 
- Neuroimaging studies examining the trajectories of brain development

- Neuroimaging studies examining the impact of behavioral treatments on the brain

(c) Continued research examining environmental risk factors, as well as geneenvironment interactions.

(d) Identification of biomarkers (e.g., genetics, neural circuitry) is a high priority. For instance, the National Institutes of Health Interagency Coordinating Committee Strategic Plan called for the identification of biological markers, which separately or in combination with behavioral markers accurately identified ASD before age 2 (Dawson and Bernier 2013).

(e) Development of novel therapeutics, e.g., creating medicine that can target core ASD symptoms.

(f) Focus on early developmental skills or early markers of development that may impact the developmental trajectory. For instance, there is evidence that early joint attention skills are important for social cognitive development and later language and adaptive skills. Further, interventions targeting joint attention have been shown to be effective. Thus, research further examining the role of joint attention skills in ASD would be beneficial. It is also important to identify other potential early developing skills that may provide early targets for intervention.

(ii) Clinical Research:

(a) Early diagnosis remains a treatment priority. The recent advances in technology (e.g., neuroimaging) and genetics suggest the next wave of advances in our ability to detect autism through the use of biomarkers and new screening tools. Thus, research examining the utility of these biomarkers in clinical contexts will be needed. The availability of predictive biomarkers could index risk for ASD before or at the onset of symptoms, thereby preventing the symptoms from developing or alleviating symptoms and improving the trajectory of outcomes.

(b) Development of more evidence-based treatment research throughout the lifespan is needed.

- A growing body of literature has shown that interventions can be associated with positive outcomes in children; however, there is still a need for studies across setting and improvements in methodological rigor.

- Little evidence is available about treatment in adolescents and adults. There is a need to develop treatment across the lifespan and determine "which" treatments are most needed and effective at the different life stages and "when" these treatments are most effective.

- Substantial scientific advances are needed to improve our understanding of which interventions are most effective for specific children with ASD and to elucidate the factors or components of interventions most associated with positive outcomes.

- Exciting potential to bring together basic science and treatment in development of new metrics/measures (e.g., predicting response to treatments - recent work on EEG/fMRI and treatment change).

(c) Very little evidence is available for specific treatment approaches in adolescents and adults; this is especially the case for evidence-based approaches to support the transition of youth with autism to adulthood. (Lounds et al. 2012). Thus, more research is needed to focus transition period.

(d) Little information exists about the aging population in ASD with virtually no information about the aged (65+). More research is needed in various areas from basic and clinical research to data/ method development and translational research. A research agenda spanning all these areas for the aging population was described in Piven and Rabins (2011). As noted earlier, the research 
priorities included developing diagnostic criteria and tools to diagnose older adults, conducting cross-sectional descriptive studies in adults of phenomenology and associated features, longitudinal studies of lifespan trajectories, neurobiological studies examining underlying changes over time, and intervention studies and mechanism to support clinical and research training in aging.

(e) Studies examining quality of life and the person, environmental, and personenvironmental interactions that lead to a thriving life.

(iii) Translational research:

(a) Need innovative solutions for training physicians, clinicians, and other professionals working with individuals with ASD throughout the lifespan. In particular, there is a serious lack of welltrained healthcare professional to serve the large number of adults with ASD. This includes multiple areas, including diagnosis and assessment of adult, mental health and medical supports, and supports for daily life.

(b) Research related to transition planning as it relates to treatment, independence, education, employment, living arrangements, mental health, and medical care.

\subsection{Data/Method Development Priorities}

(a) A shift toward longitudinal studies to better understand developmental trajectories (with attention to child and family characteristics e.g., SES, parental education)

(b) Inclusion of characteristics that might be important to outcome (e.g., IQ, language ability, etc.) so that predictors of outcome can be better elucidated, as well as a shift to focus on mediators and moderators of outcome.

(c) A shift in focus examining not only risk factors but also on factors that are protective and promote thriving. (d) Better metrics throughout the lifespan. There is an exciting potential to bring together basic science and treatment in development of new metrics/measures (e.g., predicting response to treatments as was seen in recent work on fMRI and treatment change).

(e) Development of better measures to look at outcome determination and more focus on quality of life (QOL) measures for the individual and family.

(f) Greater focus in critical or sensitive periods of development when environemntal exposures can have long-lasting effects on outcomes.

\subsection{Translational Priorities}

(a) Early diagnosis. A wide gap remains between our knowledge about best practices in ASD (e.g., screening for ASD at 18 and 24 months) and Centers for Disease Control and Prevention (CDC) data showing that the average age of diagnosis in the USA is 5 years and higher for individuals with milder forms of ASD. This is a problem given that much of the literature on early intervention shows best outcomes when intervention is initiated early (between 18 months and 5 years). This is a major challenge and will require innovative solutions and a focus on dissemination and implementation science.

(b) Better coordination of different systems related to children's health development (e.g., school and health systems).

(c) Development of physician guidelines for healthcare.

(d) Challenge in providing access to behavioral, mental health, and medical healthcare and, thus, the need for improved and expanded healthcare services with care providers who are well trained in working with individuals with ASD and their families.

(e) Innovative solutions to better serve those in remote regions or underserved population (e.g., individuals living in poverty). 
(f) Incorporating independent living skills into treatment/educational programs starting at a young age.

(g) Although our understanding of autism has increased, there is a major gap in translating this to public school settings.

(h) Development of new models/systems of care that incorporate appropriate educational, occupational and day programs for adults with ASD of all ability levels is essential.

(i) Vocational system for adults.

(j) Generic employment services do not meet the needs of individuals with ASD, therefore the need for more programs and research specific to individuals with ASD (e.g., supported employment models). Supportive employment programs - training related to general job skills, specific skills needed for a particular job, and ongoing support (e.g., job coach).

(k) Training and support for employers.

\section{Conclusions}

Taken together, there has been a tremendous growth in research in the ASD field. However, there remain a number of gaps that need to be addressed, with a particular focus on optimizing life course trajectories for individuals and populations with ASD. The principles of the life course health development framework describe health as an emergent set of developmental capacities that develop continuously over the lifespan in a complex, nonlinear process occurring in multiple dimensions, levels, and phases and are sensitive to timing. This is a valuable framework to direct the research agenda to continue to move the field forward and to improve the lives of individuals with ASD, their families, and their communities.

\section{References}

Adreon, D., \& Stella, J. (2001). Transition to middle and high school: Increasing the success of students with Asperger syndrome. Intervention in School and Clinic, 36, 266-271.

American Psychiatric Association. (1980). Diagnostic and statistical manual. Washington, DC: APA Press.
Amr, M., Raddad, D., El-Mehesh, F., Bakr, A., Sallam, K., \& Amin, T. (2012). Comorbid psychiatric disorders in Arab children with autism spectrum disorders. Research in Autism Spectrum Disorders, 6, 240-248.

Asperger, H. (1944). Die "autistichen Psychopathen" im Kindersalter. Archive fur psychiatrie und Nervenkrankheiten, 117, 76-136.

Baker, T. B., Breslau, N., Covey, L., \& Shiffman, S. (2012). DSM criteria for tobacco use disorder and tobacco withdrawal: A critique and proposed revisions for DSM-5. Addiction, 107(2), 263-275. doi:10.1111/j.1360-0443.2011.03657.x.

Ballaban-Gil, K., Rapin, I., Tuchman, R., \& Shinner, S. (1996). Longitudinal examination of the behavioral, language and social changes in a population of adolescents and young adults with autistic disorder. Pediatric Neurology, 15, 217-223.

Baron-Cohen, S. (2011). The science of evil: On empathy and the origins of cruelty. New York: Basic Books.

Beadle-Brown, J., Murphy, G., Wing, L., Gould, J., Shah, A., \& Holmes, N. (2002). Changes in social impairment for people with intellectual disabilities: A follow-up of the Camberwell cohort. Journal of Autism and Developmental Disorders, 32, 195-206.

Begovac, I., Begovac, B., Majic, G., \& Vidovic, V. (2009). Longitudinal studies of IQ stability with childhood autism-literature survey. Psychiatria Danubina, 21(3), 310-319.

Belcher, R., \& Smith, M. D. (1994). Coworker attitudes towards employees with autism. Journal of Vocational Rehabilitation, 4, 29-36.

Bennet, H. E., Wood, C. L., \& Hare, D. J. (2005). Providing care for adults with autistic spectrum disorders in learning disability services: Needs-based or diagnosis-driven? Journal of Applied Research in Intellectual Disabilities, 18, 57-64.

Billstedt, E., Gillberg, C., \& Gillberg, C. (2005). Autism after adolescents: Population-based 13- to 22-year follow-up study of 120 individuals with autism diagnosed in childhood. Journal of Autism and Developmental Disorders, 35(3), 351-360.

Billstedt, E., Gillberg, C., \& Gillberg, C. (2007). Autism in adults: Symptom patterns and early childhood predictors. Use of the DISCO in a community sample followed from childhood. Journal of Child Psychology and Psychiatry, 48(11), 1102-1110.

Billstedt, E., Gillberg, I. C., \& Gillberg, C. (2011). Aspects of quality of life in adults diagnosed with autism in childhood: A population-based study. Autism, 15(1), 7-20.

Bolton, P. F., Pickles, A., Murphy, M., \& Rutter, M. (1998). Autism, affective, and other psychiatric disorders: Patterns of familial aggregation. Psychological Medicine, 28, 385-395.

Bradley, E. A., Summers, J. A., Wood, H. L., \& Bryson, S. E. (2004). Comparing rates of psychiatric and behavior disorders in adolescents and young adults with severe intellectual disability with and without autism. Journal of Autism and Developmental Disorders, 34, 151-161. 
Brand, B. L., Lanius, R., Vermetten, E., Loewenstein, R. J., \& Spiegel, D. (2012). Where are we going? An update on assessment, treatment, and neurobiological research in dissociative disorders as we move toward the DSM-5. Journal of Trauma \& Dissociation, 13(1), 9-31.

Brereton, A. V., Tonge, B. J., \& Einfeld, S. L. (2006). Psychopathology in children and adolescents with autism compared to young people with intellectual disability. Journal of Autism and Developmental Disorders, 36, 862-870.

Brown, J. R., \& Rogers, S. J. (2003). Cultural issues in autism. In R. L. Hendren, S. Ozonoff, \& S. Rogers (Eds.), Autism spectrum disorders (pp. 209-226). Washington, DC: American Psychiatric Press.

Brugha, T. S., McManus, S., Bankart, J., Scott, F., Purdon, S., Smith, J., et al. (2011). Epidemiology of autism spectrum disorders in adults in the community in England. Archives of General Psychiatry, 68(5), 459-466.

Bryson, S. A., Corrigan, S. K., McDonald, T. P., \& Holmes, C. (2008). Characteristics of children with autism spectrum disorders who received services through community mental health centers. Autism, 12, 65-82.

Burgess, A. F., \& Gutstein, S. E. (2007). Quality of life for people with autism: Raising the standard for evaluating successful outcomes. Child and Adolescent Mental Health, 12, 80-86.

Camarena, P. M., \& Sarigiani, P. A. (2009). Postsecondary educational aspirations of high-functioning adolescents with autism spectrum disorders and their parents. Focus on Autism and Other Developmental Disabilities, 24(2), 115-128.

Cederlund, M., Hagberg, B., Billstedt, E., Gillberg, I. C., \& Gillberg, C. (2008). Asperger syndrome and autism: A comparative longitudinal follow-up study more than 5 years after original diagnosis. Journal of Autism and Developmental Disorders, 38, 72-85.

Cederlund, M., Hagberg, B., \& Gillberg, C. (2010). Asperger syndrome in adolescent and young adult males. Interview, self - And parent assessment of social, emotional, and cognitive problems. Research in Developmental Disabilities, 31, 287-298.

Centers for Disease Control and Prevention (CDC). (2014). Prevalence of Autism Spectrum disorder among children aged 8 years - Autism and Developmental disabilities monitoring network, 11 sites, United States, 2010. Morbidity and Mortality Weekly Report, 63(SS02), 1-21.

Chang, H. L., Juang, Y. Y., Wang, W. T., Huang, C. I., Chen, C. Y., \& Hwang, Y. S. (2003). Screening for autism spectrum disorder in adult psychiatric outpatients in a clinic in Taiwan. General Hospital Psychiatry, 25, 284-288.

Chawarska, K., Klin, A., \& Volkmar, F. R. (2008). Autism spectrum disorders in infants and toddlers: diagnosis, assessment, and treatment. Autism spectrum disorders in infants and toddlers: Diagnosis, assessment, and treatment (pp. 327-336, 348). New York: Guilford Press.

Chiang, H.-M., Cheung, Y. K., Hickson, L., Xiang, R., \& Tsai, L. Y. (2012). Predictive factors of participation in postsecondary education for high school leavers with autism. Journal of Autism and Developmental Disorders, 42, 685-696. doi:10.1007/ s10803-011-1297-7.

Chiri, G., \& Warfield, M. E. (2012). Unmet needs and problems accessing core health care services for children with autism spectrum disorders. Journal of Child and Maternal Health, 16, 1081-1091.

Cimera, R. E., \& Cowan, R. J. (2009). The costs of services and employment outcomes achieved by adults with autism in the US. Autism, 13(3), 285-302.

Constantino, J. N., Zhang, Y., Frazier, T., Abbacchi, A. M., \& Law, P. (2010). Sibling recurrence and the genetic epidemiology of autism. The American Journal of Psychiatry, 167(11), 1349-1356.

Creak, M. (1961). Schizophrenic syndrome in childhood. Developmental Medicine and Child Neurology, 3, 501-504.

Daniels, A. M., Rosenberg, R. E., Law, J. K., Lord, C., Kaufmann, W. E., \& Law, P. A. (2011). Stability of initial disorder diagnoses in community settings. Journal of Autism and Developmental Disorders, 41(1), 110-121.

Dawson, G., \& Bernier, R. (2013). A quarter century of progress on early detection and treatment of autism spectrum disorder. Development and Psychopathology, 25, 1455-1472.

Dawson, G., Jones, E. J., Merkle, K., Venema, K., Lowy, R., Faja, S., et al. (2012). Early behavioral intervention is associated with normalized brain activity in young children with autism. Journal of the American Academy of Child \& Adolescent Psychiatry, 51, 1150-1159.

DeMyer, M. K., Barton, S., DeMyer, W. E., Norton, J. S., Allen, J., \& Steele, R. (1973). Prognosis in autism: A follow-up study. Journal of Autism and Childhood Schizophrenia, 3, 199-246.

Devlin, B., \& Scherer, S. W. (2012). Genetic architecture in autism spectrum disorder. Current Opinion in Genetics and Development, 22, 229-237.

Devlin, B., Melhem, N., \& Roeder, K. (2011). Do common variants play a role in risk for autism? Evidence and theoretical musings. Brain Research, 1380, 78-84.

Drmic, I., Aljunied, M., \& Reaven, J. (2017). Facing your fears in schools: Implementing CBT for teens with ASD and anxiety in Singapore. Journal of Autism and Developmental Disabilities. doi:10.1007/ s10803-016-3007-y.

Drmic, I., \& Szatmari, P. (2014). Emotional dysregulation and comorbidity in Autism Spectrum Disorder. Invited review for Cutting Edge Psychiatry in Practice - Autism Issue, 1, 119-131.

Eaves, L. C., \& Ho, H. H. (2008). Young adult outcomes of autism spectrum disorders. Journal of Autism and Developmental Disorders, 38, 739-747. 
Eisenberg, L. (1956). The autistic child in adolescence. The American Journal of Psychiatry, 112, 607-612.

Elsabbagh, M., Divan, G., Koh, Y.-J., Kim, Y. S., Kauchali, S., Marcin, C., et al. (2012). Global prevalence of autism and other pervasive developmental disorders. Autism Research, 5(3), 160-179. doi: http://dx.doi. org/10.1002/aur.239.

Engstrom, I., Ekstrom, L., \& Emilsson, B. (2003). Psychosocial functioning in a group of Swedish adults with Asperger syndrome or high-functioning autism. Autism, 7(1), 99-110.

Faja, S., Webb, S. J., Jones, E., Merkle, K., Kamara, D., Bavaro, J., et al. (2012). The effects of face expertise training on the behavioral performance and brain activity of adults with high functioning autism spectrum disorders. Journal of Autism and Developmental Disorders, 42, 278-293.

Farley, M. A., McMahon, W. M., Fombonne, E., Jenson, W. R., Miller, J., Gardner, M., et al. (2009). Twentyyear outcome for individuals with autism and average or near-average cognitive abilities. Autism Research, 2, 109-118.

Fombonne, E. (2005a). Epidemiology of autistic disorder and other pervasive developmental disorders. Journal of Clinical Psychiatry, 66(Suppl 10), 3-8.

Fombonne, E. (2005b). The changing epidemiology of autism. Journal of Applied Research in Intellectual Disabilities, 18(4), 281-294. doi: http://dx.doi. org/10.1111/j.1468-3148.2005.00266.x.

Frank, A. R., \& Siltington, P. L. (2000). Young adults with mental disbailities - Does transition planning make a difference? Education and Training in Mental Retardation and Developmental Disabilities, 35, 119-134.

Fussell, E., \& Furstenberg, F. F. (2005). The transition to adulthood during the twentieth century. In R. A. Settersten, F. F. Furstenberg, \& R. G. Rumbaut (Eds.), On the frontier of adulthood: Theory, research and public policy (pp. 29-75). Chicago: University of Chicago Press.

García-Villamisar, D. A., \& Dattilo, J. (2010). Effects of a leisure pro-gramme on quality of life and stress of individuals with ASD. Journal of Intellectual Disability Research, 54, 611-619.

Garcia-Villamisar, D., Ross, D., \& Wehman, P. (2000). Clinical differential analysis of persons with autism in a work setting: A follow-up study. Journal of Vocational Rehabilitation, 14, 183-185.

García-Villamisar, D., Wehman, P., \& Navarro, M. D. (2002). Changes in the quality of autistic people's life that work in supported and sheltered employment: A 5-year follow-up study. Journal of Vocational Rehabilitation, 17, 309-312.

Gardener, H., Spiegelman, D., \& Buka, S. L. (2009). Prenatal risk factors for autism: Comprehensive metaanalysis. British Journal of Psychiatry, 195(1), 7-14.

Gerber, F., Bessero, S., Robbiani, B., et al. (2011). Comparing residential programmes for adults with autism spectrum disorders and intellectual disability: Outcomes of challenging behaviour and quality of life. Journal of Intellectual Disability Research, 55, 918-932.
Geschwind, D.H., \& State, M.W. (2015). Gene hunting in autism spectrum disorder: on the path to precision medicine. Lancet Neurology, Published online http:// dx.doi.org/10.1016/S1474-4422(15)00044-7.

Ghaziuddin, M., \& Zafar, S. (2008). Psychiatric comorbidity in adults with autism spectrum disorders. Clincial Neuropsychiatry, 5, 9-12.

Ghaziuddin, M., Weidmer-Mikhail, E., \& Ghaziuddin, N. (1998). Comorbidity of Asperger syndrome: A preliminary report. Journal of Intellectual Disability Research, 42, 278-283.

Gillberg, C. (1991). Outcome in autism and autistic-like conditions. Journal of the American Academy of Child and Adolescent Psychiatry, 30, 375-382.

Gillberg, C., \& Steffenburg, S. (1987). Outcomes and prognostic factors in infantile autism and similar conditions: A population-based study of 46 cases followed through puberty. Journal of Autism and Developmental Disorders, 17, 272-288.

Gillespie-Lynch, K., Sepeta, L., Wang, Y., Marshall, S., Gomez, L., Sigman, M., \& Hutman, T. (2012). Early childhood predictors of the social competence of adults with autism. Journal of Autism and Developmental disorder, 42, 161-174.

Gilotty, L., Kenworthy, L., Sirian, L., Black, D. O., \& Wagner, A. E. (2012). Adaptive skills and executive function in autism spectrum disorders. Child Neuropsychology, 8(4), 241-248.

Gjevik, E., Eldevik, S., Fjaeran-Granum, T., \& Sponheim, E. (2011). Kiddie-SADS reveals high rates of DSM-IV disorders in children and adolescents with autism spectrum disorders. Journal of Autism and Developmental Disorders, 41, 761-769.

Glennon, T. J. (2001). The stress of the university experience for students with Asperger syndrome. Work: Journal of Prevention, Assessment \& Rehabilitation, 17(3), 183-190.

Gulsrud, A. C., Hellemann, G. S., Freeman, F. N., \& Kasari, C. (2014). Two to ten years: Developmental trajectories of joint attention with ASD who received targeted social communication interventions. Autism Research, 7, 207-215.

Hagner, D., \& Cooney, B. F. (2005). "I do that for everybody": Supervising employees with autism. Focus on Autism and Developmental Disabilities, 20(2), 91-97.

Halfon, N., \& Forrest, C. B. (2017). The emerging theoretical framework of life course health development. In N. Halfon, C. B. Forrest, R. M. Lerner, \& E. Faustman (Eds.), Handbook of life course health-development science. Cham: Springer.

Halfon, N., Larson, K., Lu, M., Tullis, E., \& Russ, S. (2014). Lifecourse health development: Past, present and future. Journal of Maternal Child Health, 18, 344-365.

Hallmayer, J., Cleveland, S., Torres, A., Phillips, J., Cohen, B., Torigoe, T., et al. (2011). Genetic heritability and shared environmental factors among twin pairs with autism. Archives of General Psychiatry, 68(11), 1095-1102. doi:10.1001/archgenpsychiatry. 2011.76 . 
Harris, L. J., \& Handelman, J. S. (Eds.). (2000). Preschool education programs for children with autism (2nd ed.). Austin: PRO-ED.

Henninger, N. A., \& Taylor, J. L. (2012). Outcomes in adults with autism spectrum disorders: A historical perspective. Autism, O(0), 1-14. doi:10.1177/1362361312441266.

Hermelin, B. (2001). Bright Splinters of the mind: A personal story of research with Autistic savants. London: Jessica Kingsley.

Hofvander, B., Delorme, R., Chaste, P., Nyden, A., Wentz, E., Stahlberg, O., et al. (2009). Psychiatric and psychosocial problems in adults with normal-intelligence autism spectrum disorders. BMC Psychiatry, 9, 35. doi:10.1186/1471-244X-9-35.

Holden, B., \& Gitlesen, J. P. (2006). A total population study of challenging behavior in the country of Hedmark, Norway: Prevalence, and risk markers. Research in Developmental Disabilities, 27(4), 456-465.

Howlin, P. (1998). Children with autism and Asperger syndrome. A guide for practitioners and carers. Chichester: John Wiley \& Sons.

Howlin, P. (2000). Outcome in adult life for more able individuals with Autism or Asperger Syndrome. Autism, 4(1), 63-83.

Howlin, P. (2003). Outcome in high-functioning adults with autism with and without early language delays: Implications for the differentiation between autism and Asperger syndrome. Journal of Autism and Developmental Disorders, 33, 3-13.

Howlin, P. (2005). Outcomes in autism spectrum disorders. In P. Howlin (Ed.), Handbook od autism and pervasive developmental disorder, volume 1: Diagnosis, development, neurobiology, and behavior (3rd ed.). Hoboken: John Wiley \& Sons.

Howlin, P. (2013). Outcomes in adults with autism spectrum disorders. In F. Volkmar, S. Rogers, R. Paul, \& K. Pelphrey (Eds.), Handbook of autism (4th ed.). Hoboken: Wiley.

Howlin, P., \& Goode, S. (1998). Outcomes in adult life for individuals with autism. In F. Volkmar (Ed.), Autism and developmental disorders. New York: Cambridge University Press.

Howlin, P., \& Moss, P. (2012). Adults with autism spectrum disorders. Canadian Journal of Psychiatry, 57(5), 275-283.

Howlin, P., Alcock, J., \& Burkin, C. (2005). An 8 year follow-up of a specialist supported employment service for high-ability adults with autism or Asperger syndrome. Autism, 9(5), 533-549.

Howlin, P., Goode, J., Hutton, J., \& Rutter, M. (2004). Adult outcomes for children with autism. Journal of Child Psychology and Psychiatry, 45, 212-229.

Huerta, M., Bishop, S. L., Duncan, A., Hus, V., \& Lord, C. (2012). Application of the DSM-5 criteria for autism spectrum disorder to three samples of children with DSM-IV diagnoses of pervasive developmental disorders. American Journal of Psychiatry, 169(10), 1056-1064.
Jobe, L., \& White, S. W. (2007). Loneliness, social relationships, and a broader autism phenotype in college students. Personality and Individual Differences, 42, 1479-1489.

Joshi, G., Petty, C., Wozniak, J., Henin, A., Fried, R., Galdo, M., et al. (2010). The heavy burden of psychiatric comorbidity in youth with autism spectrum disorders: A large comparative study of psychiatrically referred population. Journal of Autism and Developmental Disorders, 40, 1361-1370.

Kamio, Y., Inada, N., \& Koyama, T. (2012). A nationwide survey on quality of life and associated factors of adults with high-functioning autism spectrum disorders. Autism, 17, 15-26.

Kamp-Becker, I., Schröder, J., Muehlan Remschmidt, H., et al. (2011). Health-related quality of life in children and adolescents with autism spectrum disorder. Zeitschrift für Kinder - und Jugendpsychiatrie und Psychotherapie, 39(2), 123-131.

Kanner, L. (1943). Autistic disturbances of affective contact. Nervous Child, 2, 217-250.

Kanner, L. (1971). Follow-up study of eleven autistic children originally reported in. Journal of Autism \& Childhood Schizophrenia, 1(2), 119-145.

Kasari, C., Gulsrud, A. C., Wong, C., Kwon, S., \& Locke, J. (2010). Randomized controlled caregiver mediated joint engagement intervention for toddlers with autism. Journal of Autism Developmental Disorders, 40(9), 1045-1056.

Keel, J. H., Mesibov, G. B., \& Woods, A. V. (1997). TEACCH-supported employment program. Journal of Autism and Developmental Disabilities, 27(1), 3-9.

Keogh, B. K., Bernheimer, L. P., \& Guthrie, D. (2004). Children with developmental delays twenty years later: Where are they? How are they? American Journal on Mental Retardation, 109(3), 219-230.

Kim, S.H., Macari, S., Koller, J., \& Chawarska, K. (2015). Examining the phenotypic heterogeneity of early autism spectrum disorder: Subtypes and shortterm outcomes. Journal of Child Psychology and Psychiatry. doi:10.1111/jcpp.12448.

King, M., \& Bearman, P. (2009). Diagnostic change and the increased prevalence of autism. International Journal of Epidemiology, 38(5), 1224-1234. Epub 2009 Sep 7. PubMed PMID: 19737791.

Kleinman, J., Ventola, P., Pandey, J., Verbalis, A., Barton, M., Hodgson, S., et al. (2008). Diagnostic stability in very young children with autism spectrum disorder. Journal of Autism and Developmental Disorders, 38(4), 606-615. doi:10.1007/s10803-007-0427-8.

Klin, A., Volkmar, F. R., Sparrow, S. S., Cicchetti, D. V., \& et al. (1996). Validity and neuropsychological characterization of Asperger syndrome: Convergence with nonverbal learning disabilities syndrome. Annual Progress in Child Psychiatry \& Child Development, 241-259.

Kobayashi, R., Murata, T., \& Yoshinaga, K. (1992). A follow-up study of 201 children with autism in Kyushu and Yamaguchi areas, Japan. Journal of Autism and Developmental Disorders, 22, 395-411. 
Kraemer, B. R., \& Blacher, J. (2001). Transition for young adults with severe mental retardation: School preparation, parent expectations, and family involvement. Mental Retardation, 39, 432-455.

Kraemer, B. R., McIntyre, L. L., \& Blacher, J. (2003). Quality of life for young adults with mental retardation during transition. Mental Retardation, 41, 250-262.

Kim, J., Szatmari, P., Bryson, S. E., \& Wilson, F. J. (2000). Prevalence of anxiety and mood problems among children with autism and Asperger syndrome. Autism, 4, 117-132.

LaFramboise, T., Winckler, W., \& Thomas, R. K. (2009). A flexible rank-based framework for detecting copy number aberrations from array data. Bioinformatics, 25(6), 722-728.

La Malfa, G., Lassi, S., Salvini, R., Giganti, C., Bertelli, M., \& Albertini, G. (2007). The relationship between autism and psychiatric disorders in intellectually disabled adults. Research in Autism Spectrum Disorders, 1, 218-228.

Landa, R. J., \& Kalb, L. G. (2012). Long-term outcomes of toddlers with autism spectrum disorders exposed o short-term intervention. Pediatrics, 130(2), S186S190. doi:10.1542/peds.2012-0900Q.

Landa, R. J., Holman, K. C., \& Garrett-Mayer, E. (2007). Social and communication development in toddlers with early and later diagnosis of autism spectrum disorders. Archives of General Psychiatry, 64(7), 853-864.

Landa, R. J., Holman, K. C., O’Neill, A. H., \& Stuart, E. A. (2011). Intervention targeting development of socially synchronous engagement in toddlers with autism spectrum disorder: A randomized controlled trial. Journal of Child Psychology and Psychiatry, 52(1), 13-21.

Larsen, F. W., \& Mouridsen, S. E. (1997). The outcome in children with childhood autism and Asperger syndrome originally diagnosed as psychotic. A 30-year follow-up study of subjects hospitalized as children. European Child and Adolescent Psychiatry, 6(4), 181-190.

Lee, G. K., \& Carter, E. W. (2012). Preparing transitionage students with high-functioning autism spectrum disorders for meaningful work. Psychology in the Schools, 49(10), 988-1000. doi:10.1002/pits.21651.

Leekam, S. R., Nieto, C., Libby, S. J., Wing, L., \& Gould, J. (2006). Describing the sensory abnormalities of children and adults with autism. Journal of Autism and Developmental Disorders, 37, 894-910. doi:10.1007/ s10803-006-0218-7.

Levy, A., \& Perry, A. (2011). Outcome in adolescents and adults with autism: A review of the literature. Research in Autism Spectrum Disorders, 5, 1271-1282.

Levy, S. E., Mandell, D. S., \& Schultz, R. T. (2009). Autism. Lancet, 374, 1627-1638.

Leyfer, O. T., Folstein, S. E., Bacalman, S., Davis, N. O., Dinh, E., Morgan, J., et al. (2006). Comorbid psychiatric disorders in children with autism: Interview development and rates of disorders. Journal of Autism and Developmental Disorders, 36, 849-861.
Li, X., Zou, H., \& Brown, W. T. (2012). Genes associated with autism spectrum disorder. Brain Research Bulletin, 88(6), 543-552.

Liptak, G. S., Benzoni, L. B., Mruzek, D. W., Nolan, K. W., Thingvoll, M. A., Wade, C. M., \& Fryer, G. E. (2008). Disparities in diagnosis and access to health services for children with autism: Data from the national survey of children's health. Journal of Developmental \& Behavioral Pediatrics, 29(3), 152-160.

Lockyer, L., \& Rutter, M. (1969). A five- to fifteenyear follow-up study of infantile psychosis: III. Psychological aspects. The British Journal of Psychiatry, 115, 865-882.

Lockyer, L., \& Rutter, M. (1970). A five- to fifteen-year follow-up study of infantile psychosis: IV. Patterns of cognitive ability. British Journal of Social and Clinical Psychology, 9(2), 152-163.

Loke, Y. J., Hannan, A. J., \& Craig, J. M. (2015). The role of epigenetic change in autism spectrum disorders. Frontiers in Neurology, 6, 107. doi:10.3389/ fneur.2015.00107.

Lord, C., \& Bailey, A. (2002). Autism spectrum disorders. In M. Rutter \& E. Taylor (Eds.), Child and adolescent psychiatry (4th ed., pp. 664-681). Oxford, MA: Blackwell Scientific.

Lord, C., \& Schopler, E. (1989). The role of age at assessment, developmental level, and test in the stability of intelligence scores in young autistic children. Journal of Autism and Developmental Disorders, 19(4), 483-499.

Lotter, V. (1974). Social adjustment and placement of autistic children in Middlesex: A follow-up study. Journal of Autism and Childhood Schizophrenia, 4, 11-32.

Lotter, V. (1978). Follow-up studies. In M. Rutter \& E. Schopler (Eds.), Autism: A reappraisal of concepts and treatment (pp. 475-495). New York: Plenum Press.

Lounds Taylor, J., Dove, D., Veenstra-VanderWeele, J., Sathe, N.A., McPheeters, M.L., Jerome, R.N., Warren, Z.. (2012). Interventions for adolescents and young Adults with Autism Spectrum disorders. Comparative effectiveness review no. 65. (Prepared by the Vanderbilt evidence-based practice Center under contract no. 290-2007-10065-I.) AHRQ publication no. 12-EHC063-EF. Rockville, MD: Agency for Healthcare Research and Quality. www.effectivehealthcare.ahrq.gov/reports/final.cfm

Lovaas, I. (1987). Behavioral treatment and normal educational and intellectual functioning in young autistic children. Journal of Consulting and Clinical Psychology, 55(1), 3-9.

LoVullo, S. V., \& Matson, J. L. (2009). Comorbid psychopathology in adults with autism spectrum disorders and intellectual disabilities. Research in Developmental Disabilities, 30, 1288-1296. doi:10.1016/j.ridd.2009.05.004.

Lugnegard, T., Hallerback, M. U., \& Gillberg, C. (2011). Psychiatric comorbidity in young adults with a clinical diagnosis of Asperger syndrome. Research in Developmental Disabilities, 32, 1910-1917. 
Lunsky, Y., Gracey, C., \& Bradley, E. (2009). Adults with autism spectrum disorders using psychiatric hospitals in Ontario: Clinical profile and service needs. Research in Autism Spectrum Disorders, 3, 1006-1013.

Luxford, S., Hadwin, J. A., \& Kovshoff, H. (2016). Evaluating the effectiveness of a school-based cognitive behavioural therapy intervention for anxiety in adolescents diagnosed with autism spectrum disorder. Journal of Autism and Developmental Disorders, doi:http://dx.doi.org/10.1007/s10803-016-2857-7

Magiati, I., Moss, J., Charman, T., \& Howlin, P. (2011). Patterns of change in children with autism spectrum disorders who received community based comprehensive interventions in their pre-school years: A seven year follow-up study. Research in Autism Spectrum Disorders, 5(3), 1016-1027.

Malhotra, D., \& Sebat, J. (2012). Copy number variants: Harbingers of a rare variant revolution in psychiatric genetics. Cell, 148(6), 1223-1241.

Mattila, M.-L., Hurtig, T., Haapsamo, H., Jussila, K., Kuusikko-Gauffin, S., Kielinen, M., et al. (2010). Comorbid psychiatric disorders associated with Asperger syndrome/high functioning autism: A community and clinic-based study. Journal of Autism and Developmental Disorders, 40, 1080-1093.

Mattilla, M.-L., Kielinen, M., Linna, S.-L., Jussilla, K., Ebeling, H., Bloigu, R., et al. (2011). Autism Spectrum disorders According to DSM-IV-TR and comparison with DSM-5 draft criteria an epidemiological study. Journal of the American Academy of Child \& Adolescent Psychiatry, 50(6), 583-592.

MacNeil, B. M., Lopes, V. A., \& Minnes, P. M. (2009). Anxiety in children and adolescents with autism spectrum disorders. Research in Autism Spectrum Disorders, 3, 1-21. doi:10.1016/j.rasd.2008.06.001.

Mandell, D. (2008). Psychiatric hospitalization among children with autism spectrum disorders. Journal of Autism and Developmental Disorders, 38, 1059-1065.

Marshall, C. R., Noor, A., Vincent, J. B., Lionel, A. C., Feuk, L., Skaug, J., et al. (2008). Structural variation of chromosomes in autism spectrum disorder. American Journal of Human Genetics, 82(2), 477-488.

Matson, J. L., Wilkins, J., \& Ancona, M. (2008). Autism in adults with severe intellectual disability: An empirical study of symptom presentation. Journal of Intellectual \& Developmental Disability, 33, 36-42. doi:10.1080/13668250701829837.

Mawhood, L., \& Howlin, P. (1999). The outcome of a supported employment scheme for high functioning adults with autism or Asperger syndrome. Autism, 3, 229-254.

Mawhood, L., Howlin, P., \& Rutter, M. (2000). Autism and developmental receptive language disorder-a comparative follow-up in early adult life I: Cognitive and language outcomes. Journal of Child Psychology and Psychiatry, 41, 547-559.

Mazefsky, C. A., Folstein, S. E., \& Lainhart, J. E. (2008). Overrepresentation of mood and anxiety disorders in adults with autism and their first degree relatives: What does it mean? Autism Research, 1, 193-197.
McGrew, S. G., Peters, B. R., Crittendon, J. A., \& Veenstra-VaderWeele, J. (2012). Diagnostic yield of chromosomal microarray analysis in autism primary care practice: Which guidelines to implement? Journal of Autism and Developmental Disorders, 42(8), 1582-1591.

McDougle, C. J., Erickson, C. A., Stigler, K. A., \& Posey, D. J. (2005). Neurochemistry in the pathophysiology of autism. Journal of Clinical Psychiatry, 66(Suppl $10), 9-18$.

Meyer, J. A., \& Minshew, N. J. (2002). An update on neurocognitive profiles in Asperger syndrome and high-functioning autism. Focus on Autism and Other Developmental Disabilities, 17(3), 152-160. http:// dx.doi.org/10.1177/10883576020170030501.

Moseley, D. S., Tonge, B. J., Brereton, A. V., \& Einfeld, S. L. (2011). Psychiatric comorbidity in adolescents and young adults with autism. Journal of Mental Health Research in Intellectual Disabilities, 4, 229-243.

Mouridsen, S. E., Rich, B., Isager, T., \& Nedergaard, N. J. (2008). Psychiatric disorders in individuals diagnosed with infantile autism as children: A case control study. Journal of Psychiatric Practice, 14, 5-12.

Muller, N., Myint, A., \& Schwarz, M. J. (2015). Immunology and psychiatry: From basic research to therapeutic interventions. Cham: Springer International Publishing.

Mundy, P., \& Jarrold, W. (2010). Infant joint attention, neural networks and social cognition. Neural Networks, 23, 985-997. doi:10.1016/j.neunet.2010.08.009.

Mundy, P., Sullivan, L., \& Mastergeorge, A. M. (2009). A parallel and distributed processing model of joint attention, social cognition, and autism. Autism Research, 2, 2-21.

Muris, P., Steerneman, P., Merckelbach, H., Holdrinet, I., \& Meesters, C. (1998). Comorbid anxiety symptoms in children with pervasive developmental disorders. Journal of Anxiety Disorders, 12, 387-393.

Narendorf, S. C., Shattuck, P. T., \& Sterzing, P. R. (2011). Mental health services among adolescents with an autism spectrum disorder. Psychiatric Services, 62, 975-978.

National Autism Center. (2015). Findings and conclusions: National standards project, phase 2. Randolph, MA: Author.

National Autism Center. (2009). National Standards Report - Addressing the need for evidence-based practice guidelines for Autism Spectrum Disorders. Massachusetts: National Autism Center.

National Research Council. (2001). Educating young children with autism. Washington, DC: National Academy Press.

Newman, L., Wagner, M., Knokey, A. M., Marder, C., Nagle, K., Shaver, D., \& Wei, X. (2011). The posyhigh school outcomes of young adults with disabilities up to 8 years after high school. Menlo Park: SRI International.

Nordin, V., \& Gillberg, C. (1998). The long-term course of autistic disorders: Update on follow-up studies. Acta Psychiatrica Scandinavica, 97, 99-108. 
Noterdaeme, M., Wriedt, E., \& Höhne, C. (2010). Asperger's syndrome and high-functioning autism: Language, motor and cognitive profiles. European Child \& Adolescent Psychiatry, 19(6), 475-481.

Palac, S., \& Meador, K. J. (2011). Antiepileptic drugs and neurodevelopment: An update. Current Neurology and Neuroscience Reports, 11(4), 423-427.

Palucka, A. M., Bradley, E., \& Lunsky, Y. (2008). A case of unrecognized intellectual disability and autism misdiagnosed as schizophrenia: Are there lessons to be learned? Mental Health Aspects of Developmental Disabilities, 11(2), 55-60.

Parr, J. R., Le Couteur, A., Baird, G., Rutter, M., Pickles, A., Fombonne, E., Bailey, A. J., \& International Molecular Genetic Study of Autism Consortium. (2011). Early developmental regression in autism spectrum disorder: Evidence from an international multiplex sample. Journal of Autism \& Developmental Disorders, 41(3), 332-340.

Paul, R. (2008). Communication development and assessment. In K. Chawarska, A. Klin, \& F. Volkmar (Eds.), Autism Spectrum disorders in infants and toddlers: Diagnosis, Assessment, and treatment (pp. 76-103). New York: Guilford Press.

Pinto, D., Pagnamenta, A. T., Klei, L., Anney, R., Merico, D., Regan, R., et al. (2010). Functional impact of global rare copy number variation in autism spectrum disorders. Nature, 466(7304), 368-372.

Piven, J., \& Rabins, P. (2011). Autism spectrum disorders in older adults: Toward defining a research agenda. Journal of the American Geriatrics Society, 59(11), 2151-2155.

Perkins, E. A., \& Berkman, K. A. (2012). Into the unknown: Aging with autism spectrum disorders. American Journal on Intellectual and Developmental Disabilities, 117(6), 478-496.

Perlman, L. (2000). Adults with Asperger disorder misdiagnosed as schizophrenic. Professional Psychology: research \& Practice, 31(2), 221-225. False.

Peters-Scheffer, N., Didden, R., Hubert, K., \& Sturmey, P. (2011). A meta-analytic study on the effectiveness of comprehensive ABA-based early intervention programs for children with Autism Spectrum disorders. Research in Autism Spectrum Disorders, 5(1), 60-69.

Polloway, E. A., Patton, J. R., \& Serna, L. (2001). Strategies for teaching learners with special needs. Upper Saddle River: Merrill Prentice Hall.

Potvin, M. C., Snider, L., Prelock, P. A., Wood-Dauphinee, S., \& Kehayia, E. (2015). Health-related quality of life in children with high-functioning autism. Autism, 19(1), 14-19.

Power, R. A., Kyaga, S., Uher, R., Maccabe, J. H., Långström, N., Landen, M., et al. (2012). Fecundity of patients with schizophrenia, Autism, bipolar disorder, depression, anorexia nervosa, or substance abuse vs their unaffected siblings. Archives of General Psychiatry, 12, 1-8.

Raphael, D., Brown, I., Renwick, R., \& Rootman, I. (1996). Assessing the quality of life of persons with developmental disabilities: Description of a new model, measuring instruments, and initial findings. International Journal of Diability, 43(1), 25-42.

Reichow, B. (2012). Overview of meta-analyses on early intensive behavioral intervention for young children with autism spectrum disorders. Journal of Autism and Developmental Disorders, 42, 512-520.

Reichow, B., \& Wolery, M. (2009). Comprehensive synthesis of early intensive behavioral interventions for young children with autism based on the UCLA young Autism Project model. Journal of Autism and Developmental Disorders, 39(1), 23-41.

Renty, J., \& Roeyers, H. (2006). Quality of life in highfunctioning adults with autism spectrum disorder: The predictive value of disability and support characteristics. Autism, 10, 511-524.

Ritvo, E. R., Jorde, L. B., Mason-Brothers, A., Freeman, B. J., Pingree, C., Jones, M. B., et al. (1989). The UCLAUniversity of Utah epidemiologic survey of autism: Recurrence risk estimates and genetic counseling. American Journal of Psychiatry, 146(8), 1032-1036.

Robinson, S., Goddard, L., Dritschel, B., Wisley, M., \& Howlin, P. (2009). Executive functions in children with autism spectrum disorders. Brain and Cognition, 71(3), 362-368. http://dx.doi.org/10.1016/j. bandc.2009.06.007

Rogers, S. J. (2009). What are infant siblings teaching us about autism in infancy? Autism research : Official Journal of the International Society for Autism Research, 2(3), 125-137.

Rondeau, E., Klein, L. S., Masse, A., Bodeau, N., Cohen, D., \& Guile, J.-M. (2011). Is pervasive developmental disorder not otherwise specified less stable than autistic disorder? A meta-analysis. Journal of Autism and Developmental Disorders, 41, 1267-1276.

Ruble, L. A., \& Dalrymple, N. J. (1996). An alternative view of outcome in autism. Focus on Autism and Other Developmental Disabilities, 11(1), 3-14.

Rumsey, J. M., Rapoport, J. L., \& Sceert, W. R. (1985). Autistic children as adults: Psychiatric, social, and behavioral outcomes. Journal of the American Academy of Child Psychiatry, 24(4), 465-473.

Russ, S. A., Larson, K., Tullis, E., \& Halfon, N. (2014). A lifecourse approach to health development: Implications for the maternal and child health research agenda. Maternal and Child Health Journal, 18(2), 497-510.

Russell, E., \& Sofronoff, K. (2005). Anxiety and social worries in children with Asperger syndrome. Australian and New Zealand Journal of Psychiatry, 39, 633-638.

Rutter, M. (1967). The autistic child. Royal Institute of Public Health \& Hygiene Journal, 30(4), 130-132.

Rutter, M. (1973). Why are London children so disturbed? Proceedings of the Royal Society of Medicine, 66(12), 1221-1225.

Rutter, M. (1978). Diagnosis and definition of childhood autism. Journal of Autism \& Childhood Schizophrenia, $8(2), 139-161$.

Rutter, M. (1982). Prevention of children's psychosocial disorders: Myth and substance. Pediatrics, 70(6), 883-894. 
Rutter, M. (2005). Environmentally mediated risks for psychopathology: Research strategies and findings. Journal of the American Academy of Child \& Adolescent Psychiatry, 44(1), 3-18.

Rutter, M., \& Lockyer, L. (1967). A five to fifteen year follow-up study of infantile psychosis I. Description of sample. British Journal of Psychiatry, 113(504), 1169-1182.

Rutter, M., Greenfield, D., \& Lockyer, L. (1967). A five to fifteen year follow-up of infantile psychosis II social and behavioral outcome. The British Journal of Psychiatry, 113, 1183-1199.

Schreibman, L., Dawson, G., Stahmer, A. C., Landa, R., Rogers, S., et al. (2015). Naturalistic developmental behavioral interventions: Empirically validated treatments for autism spectrum disorder. Journal of Autism and Developmental Disorders, 45(8), 2411-2428.

Saxena, S., \& Orley, J. (1997). Quality of life assessment: The world health organization perspective. European Psychiatry, 12, 263s-266s.

Schumann, C. M., Bloss, C. S., Barnes, C. C., Wideman, G. M., Carper, R. A., Akshoomoff, N., et al. (2010). Longitudinal magnetic resonance imaging study of cortical development through early childhood in autism. Journal of Neuroscience, 30, 4419-4427.

Seltzer, M. M., Krauss, M. W., Shattuck, P. T., Orsmond, G., Swe, A., \& Lord, C. (2003). The stmptoms of autism spectrum disorders in adolescents and adulthood. Journal of Autism and Developmental Disorders, 33, 565-581.

Seltzer, M. M., Shattuck, P., Abbeduto, L., \& Greenberg, J. S. (2004). Trajectory of development in adolescents and adults with autism. Mental Retardation and Developmental Disabilities, 10, 234-247.

Shattuck, P. T., Durkin, M., Maenner, M., Newschaffer, C., Mandell, D. S., Wiggins, L., et al. (2009). Timing of identification among children with an autism spectrum disorder: Findings from a population-based surveillance study. Journal of the American Academy of Child \& Adolescent Psychiatry, 48(5), 474-483.

Shattuck, P. T., Roux, A. M., Hudson, L. E., Taylor, J. L., Maenner, M. J., \& Trani, J.-F. (2012). Services for adults with autism spectrum disorder. Canadian Journal of Psychiatry, 57(5), 284-291.

Shattuck, P. T., Seltzer, M. M., Greenberg, J. S., Orsmond, G. I., Bolt, D., Kring, S., et al. (2007). Change in autism symptoms and maladaptive behaviors in adolescents with an autism spectrum disorder. Journal of Autism and Developmental Disorders, 37, 1735-1747.

Shelton, J. F., Tancredi, D. J., \& Hertz-Picciotto, I. (2010). Independent and dependent contributions of advanced maternal and paternal ages to autism risk. Autism Research, 3(1), 30-39.

Sigman, M., \& Kasari, C. (1995). Joint attention across contexts in normal and autistic children. (pp. 189203). Hillsdale: Lawrence Erlbaum Associates, Inc. Retrieved from http://search.proquest.com/docview/6 18769168 ?accountid=14771

Sigman, M., \& McGovern, C. W. (2005). Improvement in cognitive and language skills from preschool to adoles- cence in autism. Journal of Autism and Developmental Disorders, 35(1), 15-23.

Sigman, M., \& Ruskin, E. (1999). Continuity and change in the social competence of children with autism, down syndrome, and developmental delays. Monographs of the Society for Research in Child Development, 64(1), $1-139$.

Simonoff, E., Pickles, A., Charman, T., Chandler, S., Loucas, T., \& Baird, G. (2008). Psychiatric disorders in children with autism spectrum disorders: Prevalence, comorbidity, and associated factors in a populationderived sample. Journal of the American Academy of Child and Adolescent Psychiatry, 47, 921-929.

Skokauskas, N., \& Gallagher, L. (2010). Psychosis, affective disorders, and anxiety in autistic spectrum disorder: Prevalence and nosological considerations. Psychopathology, 43, 8-16.

Smith, M., \& Paulippen, L. (1999). Community integration and supported employment. In D. Zager (Ed.), Autism: Identification, education, treatment (pp. 301319). Mahwah: Erlbaum.

State, M. W. (2010). The genetics of child psychiatric disorders: Focus on autism and Tourette syndrome. Neuron, 68(2), 254-269.

Sterling, L., Dawson, G., Estes, A., \& Greenson, J. (2008). Characteristics associated with presence of depressive symptoms in adults with autism spectrum disorder. Journal of Autism and Developmental Disorders, 38, 1011-1018.

Stoner, J. B., Angell, M. E., House, J. J., \& Bock, S. J. (2007). Transitions: Perspectives from parents of young children with autism spectrum disorders (ASD). Journal of Developmental Disabilities, 19, 23-39.

Strauss, K., Mancini, F., \& Fava, L. (2013). Parent inclusion in early intensive behavior interventions for young children with ASD: A synthesis of meta-analyses from 220 to 2011. Reseach in Developmental Disabilities, 34(9), 2967-2985.

Sullivan, P. F., Daly, M. J., \& O'Donovan, M. (2012). Genetic architectures of psychiatric disorders: The emerging picture and its implications. Nature Reviews Genetics, 13(8), 537-551.

Sun F, Oristaglio J, Levy SE, Hakonarson H, Sullivan N, Fontanarosa J, Schoelles KM. 2015. Genetic testing for developmental disabilities, intellectual disability, and Autism Spectrum disorder. Technical brief no. 23. (prepared by the ECRI institute-Penn medicine evidence-based practice Center under contract no. 290-2012-00011-I.) AHRQ publication no.15EHC024-EF. Rockville, MD: Agency for Healthcare Research and Quality. www.effectivehealthcare.ahrq. gov/reports/final.cfm.

Szatmari, P. (2011). New recommendations on autism spectrum disorder shifting the focus from subtypes to dimensions carriers potential costs and benefits. $B M J$, 342. doi:10.1136/bmj.d2456.

Szatmari, P., \& McConnell, B. (2011). Anxiety and mood disorders in individuals with autism spectrum disorder. In D. G. Amaral, G. Dawson, \& D. H. Geschwind 
(Eds.), Autism spectrum disorders (pp. 330-338). New York: Oxford University Press, Inc.

Szatmari, P., Bartolucci, G., Brenner, R., Bond, S., \& Rich, S. (1989). A follow-up study of high-functioning autistic children. Journal of Autism and Developmental Disorders, 19, 213-225.

Szatmari, P., Bryson, S. E., Boyle, M. H., Streiner, D. L., $\&$ Duku, E. (2003). Predictors of outcome among high functioning children with autism and Asperger syndrome. Journal of Child Psychology and Psychiatry, 44(4), 529-528.

Szatmari, P., Georgiades, S., Duku, E., Bennett, T. A., Bryson, S., et al. (2015). Developmental trajectories of symptom severity and adaptive functioning in an inception cohort of preschool children with autism spectrum disorder. JAMA Psychiatry, 72(3), 276-283.

Szatmari, P., Jones, M. B., Zwaigenbaum, L., \& MacLean, J. E. (1998). Genetics of autism: Overview and new directions. Journal of Autism and Developmental Disorders, 28(5), 351-368.

Szatmari, P., Paterson, A. D., Zwaigenbaum, L., Roberts, W., Brian, J., Autism Genome Project Consortium, et al. (2007). Mapping autism risk loci using genetic linkage and chromosomal rearrangements. Nature Genetics, 39(3), 319-328.

Taylor, J. L. (2009). The transition out of high school and into adulthood for individuals with autism and for their families. International Review of Research in Mental Retardation, 38, 1-32. doi:10.1016/ S0074-7750(08)38001-X.

Taylor, J. L., \& Seltzer, M. M. (2010). Changes in the autism behavioral phenotype during the transition to adulthood. Journal of Autism and Developmental Disorders, 40, 1431-1446.

Taylor, J. L., \& Seltzer, M. M. (2011a). Changes in the mother-child relationship during the transition to adulthood for youth with autism spectrum disorders. Journal of Autism and Developmental Disorders, 41, 1397-1410. doi:10.1007/s10803-010-1166-9.

Taylor, J. L., \& Seltzer, M. M. (2011b). Employment and post-secondary educational activities for young adults with autism spectrum disorders during the transition to adulthood. Journal of Autism and Developmental Disorders, 41, 566-574.

Taylor, J. L., McPheeters, M. L., Sathe, N. A., Dove, D., Veenstra-VanderWeele, J., \& Warren, Z. (2012). A systematic review of vocational interventions for young adults with autism spectrum disorders. Pediatrics, 130(3), 531-538. doi:10.1542/peds.2012-0682.

Thomas, K. C., Ellis, A. R., McLaurin, C., Daniels, J., \& Morrissey, J. P. (2007). Access to care for autismrelated services. Journal of Autism and Developmental Disorders, 37, 1902-1912.

Totsika, V., Flece, D., Kerr, M., \& Hastings, R. P. (2010). Behavior problems, psychiatric symptoms, and quality of life for older adults with intellectual disability with and without autism. Journal of Autism and Developmental Disorders, 40, 1171-1178.
Tomasello, M. (1995). Joint attention as social cognition. In C. Moore, \& P. J. Dunham (Eds.), Joint attention: Its origins and role in development; joint attention: Its origins and role in development (pp. 103-130, Chapter vii, 286 Pages). Hillsdale: Lawrence Erlbaum Associates, Inc.

Towbin, K. E. (2005). Pervasive developmental disorder not otherwise specified. In F. R. Volkmar, A. Klin, R. Paul, \& D. J. Cohen (Eds.), Handbook of autism and pervasive developmental disorders (Vol. 1, 3rd ed., pp. 165-200). Hoboken: Wiley.

Tsakanikos, E., Costello, H., Holt, G., Bouras, N., Sturmey, P., \& Newton, T. (2006). Psychopathology in adults with autism and intellectual disability. Journal of Autism and Developmental Disorders, 36, 1123-1129.

Tsakanikos, E., Costello, H., Holt, G., Sturmey, P., \& Bouras, N. (2007a). Behavior management problems as predictors of psychotropic medication and use of psychiatric services in adults with autism. Journal of Autism and Developmental Disorders, 37, 1080-1085.

Tsakanikos, E., Sturmey, P., Costello, H., Holt, G., \& Bouras, N. (2007b). Referral trends in mental health services for adults with intellectual disability and autism spectrum disorders. Autism, 11, 9-17.

Turner, L. M., \& Stone, W. L. (2007). Variability in outcome for children with an ASD diagnosis at age 2. The Journal of Child Psychology and Psychiatry, 48(8), 793-802.

Van Acker, R., Loncola, J. A., \& Van Acker, E. Y. (2005). Rett syndrome: A pervasive developmental disorder. In F. R. Volkmar, R. Paul, A. Klin \& D. Cohen (Eds.), Handbook of autism and pervasive developmental disorders: Diagnosis, development, neurobiology, and behavior (vol. 1) (3rd ed) (pp. 126-164, Chapter xxv, 703 Pages). Hoboken: John Wiley \& Sons Inc.

VanBergeik, E., Klin, A., \& Volkmar, F. (2008). Supporting more able students on the autism spectrum: College and beyond. Journal of Autism and Developmental Disorders, 38, 1359-1370. doi:10.1007/s10803-007-0524-8.

van Heijst, B. F. C., \& Geurts, H. M. (2015). Quality of life in autism across the lifespan: A meta-analysis. Autism, 19(2), 158-167. doi:10.1177/1362361313517053.

Vaughan Van Hecke, A., Mundy, P., Acra, C. F., Block, J. J., Delgado, C. E. F., Parlade, M. V., et al. (2007). Infant joint attention, temperament, and social competence in preschool children. Child Development, 78(1), 53-69.

Veltman, J. A., \& Brunner, H. G. (2012). De novo mutations in human genetic disease. Nature Reviews Genetics, 13(8), 565-575.

Venter, A., Lord, C., \& Schopler, E. (1992). A follow-up study of high-functioning autistic children. Journal of Child Psychology and Psychiatry, 33(3), 489-507.

Volkmar, F. R. (2004). Adolescence and sexuality. In F. R. Volkmar \& L. A. Wiesner (Eds.), Healthcare for children on the autism spectrum (pp. 245-260). New York: Harbour House. 
Volkmar, F. R., \& McPartland, J. (2014). From Kanner to DSM-5: Autism as an evolving diagnostic concept. Annual Review of Clinical Psychology, 10, 193-212.

Volkmar, F. R., \& Cohen, D. J. (1991). Comorbid association of autism and schizophrenia. The American Journal of Psychiatry, 148(12), 1705-1707.

Volkmar, F. R., Koenig, K., \& State, M. (2005). Childhood disintegrative disorder. In F. R. Volkmar, A. Klin, R. Paul, \& D. J. Cohen (Eds.), Handbook of autism and pervasive developmental disorders (Vol. 1, 3rd ed., pp. 70-78). Hoboken: Wiley.

Volkmar, F. R., Klin, A., \& McPartland, J. (2014). Asperger's syndrome: An overview. In J. McPartland, A. Klin, \& F. Volkmar (Eds.), Asperger syndrome: Assessing and treating high-functioning autism spectrum disorders (pp. 1-42). New York: Guilford Press.

Watts, G. (2012). More psychiatrists attack plans for DSM-5. BMJ, 344, e3357. http://dx.doi.org/10.1136/ bmj.e3357

Weitlauf, A.S., McPheeters, M.L., Peters, B., Sathe, N., Travis, R., Aiello, R., Williamson, E., VeenstraVanderWeele, J., Krishnaswami, S., Jerome, R., Warren, Z. (2014). Therapies for Children With Autism Spectrum Disorder: Behavioral Interventions Update. Comparative Effectiveness Review No. 137. (Prepared by the Vanderbilt Evidence-based Practice Center under Contract No. 290-2012-00009-I.) AHRQ Publication No. 14-EHC036-EF. Rockville, MD: Agency for Healthcare Research and Quality. www.effectivehealthcare.ahrq.gov/reports/final.cfm
Wing, L. (1980). Childhood autism and social class: a question of selection? British Journal of Psychiatry, 137, 410-417.

White, S., Oswald, D., Ollendick, T., \& Scahill, L. (2009). Anxiety in children and adolescents with ASD. Clinical Psychology Review, 29, 216-229.

Wolff, J. J., Gu, H., Elison, J. T., Styner, M., Gouttard, S., et al. (2012). Differences in white matter fiber tract development present from 6 to 24 months in infants with autism. The American Journal of Psychiatry, 169, 589-600.

Woodbury-Smith, M. R., \& Volkmar, F. R. (2009). Asperger syndrome. European Child \& Adolescent Psychiatry, 18(1), 2-11.

Woolfenden, S., Sarkozy, V., Ridley, G., \& Williams, K. (2012). A systematic review of the diagnostic stability of autism spectrum disorder. Research in Autism Spectrum Disorders, 6, 345-354. doi:10.1016/j. rasd.2011.06.008.

Zachor, D. A., \& Itzchak, E. B. (2010). Treatment approach, autism severity and intervention outcomes in young children. Research in Autism Spectrum Dosorders, 4(3), 425-432.

Zwaigenbaum, L., Bryson, S. E., Szatmari, P., Brian, J., Smith, I. M., Roberts, W., et al. (2012). Sex differences in children with autism spectrum disorder identified within a high-risk infant cohort. Journal of Autism and Developmental Disorders, 42(12), 2585-2596.

Open Access This chapter is licensed under the terms of the Creative Commons Attribution 4.0 International License (http://creativecommons.org/licenses/by/4.0/), which permits use, sharing, adaptation, distribution and reproduction in any medium or format, as long as you give appropriate credit to the original author(s) and the source, provide a link to the Creative Commons license and indicate if changes were made.

The images or other third party material in this chapter are included in the chapter's Creative Commons license, unless indicated otherwise in a credit line to the material. If material is not included in the chapter's Creative Commons license and your intended use is not permitted by statutory regulation or exceeds the permitted use, you will need to obtain permission directly from the copyright holder. 